\title{
EVOLUCIÓN HISTÓRICA DE LOS ATENEOS EN CATALUNYA (1836-1936)
}

\section{HISTORICAL EVOLUTION OF ATENEUMS IN CATALONIA (1836-1936)}

\author{
Ramón Arnabat-Mata \\ Grupo de investigación ISOCAC, Universitat Rovira i Virgili, España \\ orcid.org/0000-0001-7924-6860 \\ Xavier Ferré-Trill \\ Grupo de investigación ISOCAC, Universitat Rovira i Virgili, España \\ orcid.org/0000-0002-8042-1184
}

Recibido el 22-11-2016 y aceptado el 11-4-2017

Resumen: El objeto de este texto es ofrecer una síntesis panorámica de los orígenes y evolución de los ateneos en Catalunya a partir de referencias estadísticas originales fruto de un listado exhaustivo de asociaciones ateneístas. El comentario de los datos agrupados sirve para establecer como resultado final una caracterización de los ateneos denotativa de una vía articulada en torno a una concepción político-cultural. Para ello partimos del ámbito cronológico determinante en este aspecto - 1836-1936 - analizado en tres grandes etapas: constituyente (1836-1886); consolidativa (1887-1900) y expansiva (1901-1936).

Palabras clave: Sociabilidad, ateneos, formación político-cultural, ciudadanía, Catalunya.

\footnotetext{
Abstract: The purpose of this is to offer a panoramic synthesis of the origins and evolution of the athenaeums in Catalonia from original statistical references resulting from an exhaustive list of atheneist associations. The commentary of the grouped data serves to establish as a final result a characterization of the athenaeums denotative of a way articulated around a political-cultural conception. For this we start from the chronological sphere determining in this as-
} 
pect - 1836-1936 - analyzed in three great stages: constituent (1836-1886); consolidative (1887-1900) and expansive (1901-1936).

Keywords: Sociability, cultural associations, political cultures formation, citizenship, Catalonia. 


\section{Presentación}

Los ateneos emergen en Catalunya durante el segundo tercio del siglo XIX en torno a una formación social en la que las relaciones sociales capitalistas condicionan los ámbitos de la economía y conforman las clases sociales. Este panorama, en el marco de un proceso prolongado de industrialización rural y urbana, configura el inicio de núcleos urbanos y periurbanos donde se materializan las luchas sociopolíticas y nacen los espacios de sociabilidad y el asociacionismo contemporáneo. El carácter de dichas contradicciones - la formación de burguesía(s) industrial(es) y agraria(s) y la consolidación de una clase subalterna entre proletaria, menestral, jornalera agraria y de trabajo en aparcería - define concepciones de la realidad que buscan hegemonizar posiciones políticas ${ }^{1}$. Es en este marco donde surgen sociabilidades formales e informales que tienen como objetivo aglutinar voluntades cívico-políticas en base a la socialización de imaginarios intelectuales que se traducen en asociaciones que abarcan diversos ámbitos de la vida social: la educación, la cultura, el ocio, el deporte, el canto coral, el excursionismo².

Para exponer dicha panorámica asociativa en clave ateneísta partimos de la base de datos de elaboración propia Base de Dades de l'Associacionisme Català Contemporani, 1870-1980 (BDACC) ${ }^{3}$. Este banco estadístico nos ha permitido registrar de modo general 1.746 entidades culturales, instructivas y/o recreativas que se crearon en Catalunya entre 1836 y 1936, de les cuales 986 (un 56,5\%) eran de recreo y 760 (un $43,5 \%$ ) culturales e instructivas. En cuanto a las denominaciones de las entidades, las clásicas de ateneo y casino representen una cuarta parte del total: 267 asociaciones (un $15,5 \%$ ) se denominan ateneos y 140 (un 8\%) se denominan casinos. Otra cuarta parte de las entidades, 416, se denominan centres y un 16\%, 280 se denominan sociedades. A continuación encontramos los círculos: 184 entidades (10,5\%), las corales y los orfeones:

1 Una visión de conjunto en Fontana, 1987, 2003, 2007 y 2016.

${ }^{2}$ En este artículo concebimos los ateneos dentro de la sociabilidad formal (con sus estatutos y reglamento), aunque en su modelo pedagógico quedan emplazados en el ámbito de sociabilidad no formal.

${ }^{3}$ Base de Dades de l'Associacionisme Català Contemporani, 1870-1980 (BDACC) del grupo de investigación ISOCAC-URV. Los datos proceden, fundamentalmente, de los Fondos de Asociaciones de los Archivos históricos de los Gobiernos Civiles de Barcelona, Girona, Lleida y Tarragona; y de diversos legajos del Archivo Histórico Nacional y del Archivo General de la Administración. 
$94(5,5 \%)$, los casals con 58 (un 3\%) y las asociaciones (29, un 1,5\%). Además 278 entidades (un 16\%) tienen otras denominaciones (uniones, fomentos, patronatos, agrupaciones, hermandades, grupos y otras) (ver el cuadro 1$)^{4}$.

\section{Cuadro 1}

Denominaciones de las asociaciones culturales y recreativas Catalunya, 1836-1936

\begin{tabular}{ccccccccccc}
\hline Período & $\begin{array}{c}\text { Asocia- } \\
\text { ción }\end{array}$ & Ateneo & Casal & Casino & Centro & Círculo & $\begin{array}{r}\text { Coral/ } \\
\text { Orfeón }\end{array}$ & $\begin{array}{r}\text { Socie- } \\
\text { dad }\end{array}$ & Otras* & Total \\
\hline $1836-1886$ & 7 & 39 & 2 & 78 & 82 & 56 & 15 & 67 & 38 & 384 \\
$1887-1900$ & 4 & 30 & 0 & 36 & 100 & 93 & 7 & 58 & 57 & 385 \\
$1901-1936$ & 18 & 198 & 56 & 26 & 234 & 35 & 72 & 155 & 183 & 977 \\
\hline Total & 29 & 267 & 58 & 140 & 416 & 184 & 94 & 280 & 278 & 1.746 \\
\hline$\%$ & $1,5 \%$ & $15,5 \%$ & $3 \%$ & $8 \%$ & $24 \%$ & $10,5 \%$ & $5,5 \%$ & $16 \%$ & $16 \%$ & $100 \%$ \\
\hline
\end{tabular}

* Incluye: agrupación, fomento, hermandad, grupo, patronato, unión y otros.

Fuente: Elaboración propia a partir de la BDACC del ISOCAC-URV.

De lo expuesto cuantitativamente nos limitaremos a reflexionar sobre la franja «Ateneo» ${ }^{5}$ en el período $1836-1936$. El objetivo de este estudio no es otro que caracterizar la dinámica de formación y desarrollo de la estructura ateneísta en Catalunya. Este tipo de asociación se desarrolló en paralelo a otros tipos de asociaciones: mutuales y cooperativas; sindicales, patronales y profesionales; y políticas y religiosas. Lo cual, con cronologías e intensidades territoriales diversas, incidió en el conjunto del estado español ${ }^{6}$.

4 Arnabat y Ferré, 2015, p. 208-229.

5 Utilizamos los términos «ateneo», «asociación ateneística» o «movimiento ateneístico», para referirnos a aquellas entidades que cumplen funciones culturales, instructivas y formativas, y/o recreativas o al conjunto de ellas, más allá de que se autodenominen como tales.

${ }^{6}$ Ver al respecto, entre otros, Maurice et al, 1989, p. 133-471. Guereña et. al, 2003, p. 407-774. Guereña, 2005. Grupo de Estudios de Asociacionismo y Sociabilidad (GEAS), 1998. Sánchez y Villena (Eds.), 1999. Valín (Dir.), 2001. Maza (Coord.), 2002 y 2003; 


\section{Tiempos y espacios del ateneísmo}

La promulgación de la Ley de Asociaciones en 1887, marca un antes y un después por lo que hace al movimiento ateneístico ${ }^{7}$. Partiendo de las condiciones de posibilidad de dicho marco legislativo establecemos la cuantificación que sigue en cuanto a número y porcentaje de concentración ateneísta por cada período.

\section{Cuadro 2}

Ateneos (Catalunya, 1836-1936)

\begin{tabular}{cccc}
\hline Período & Culturales & Recreativos & Totales \\
\hline $1836-1886$ & 141 & 243 & 384 \\
$1887-1900$ & 111 & 274 & 385 \\
$1901-1936$ & 508 & 469 & 977 \\
\hline Total & 760 & 986 & 1.746 \\
\hline$\%$ & $43,5 \%$ & $56,5 \%$ & $100 \%$ \\
\hline
\end{tabular}

Fuente: Elaboración propia a partir de Arnabat y Ferré, 2015 y BDACC.

Como vemos en el cuadro 2, entre 1836 y 1936 se crean en Catalunya 1.746 entidades culturales-recreativas: $760(43,5 \%)$ básicamente culturales y $986(56,5 \%)$ básicamente recreativas. Aunque esta nítida distinción no existía en muchas entidades que combinaban las actividades culturales y las recreativas. Por lo que hace a la cronología de la fundación de estas entidades, pueden distinguirse tres grandes etapas: la constituyente (1836-1886) con la creación de 384 entidades, con una media anual de 7,5; la consolidativa (1887-1900) con la formación de 385 nuevas asociaciones, con una media de 27,5 anuales; y la expansiva (1901-1936) con 977 nuevas entidades, con una media anual de 27 y que, a su vez podemos dividir en dos períodos: 1901-1920 con 512 nuevas entidades, y 1921-1936 con $465^{8}$.

Maza, 1995, p. 297-314 y 1997, p. 73-102. Carrasco (Ed.), 1991. Martin y Brenot (Eds.), 2000. Bussy-Genevois (Ed.), 2002. Mato, 2008.

7 Alarcón, 1975.

${ }^{8}$ Los datos en Arnabat y Ferré, 2015, p. 41-210 y en la BDACC [ISOCAC-URV]. 
Durante el período 1860-1936, según los datos de la BDACC, se inscribieron oficialmente 31.771 asociaciones en toda Catalunya que, en 1910, contaba con 2.085.000 habitantes ${ }^{9}$. Durante el último cuarto del siglo XIX el asociacionismo irradió en la sociedad catalana y durante el primer tercio del siglo Xx, Catalunya contaba con una densa red societaria, tanto por el número de asociaciones constituidas, cómo por el número de socios que estas tenían.

El grupo más numeroso era el de las entidades culturales y/o recreativas, con un 34\% del total, formado por las asociaciones de carácter cultural entre la cuales, los ateneos (un 15\%), siguen las entidades de tipo recreativo (un 12,5\%) - destacando las sociedades recreativas de los pueblos, pero también los centros excursionistas, los casinos y las peñas - e instructivo/educativo (un 6,5\%). Seguidas del grupo que conformaban las sociedades de socorros mutuos (un 19\%) y de cooperación (un 8\%). A continuación, el grupo de las asociaciones profesionales y sindicales (un $21 \%$ ) - entre las cuales sobresalían las obreras - . Y, finalmente, el grupo de las asociaciones políticas y religiosas (un 18\%), donde destacaban los partidos políticos y sus secciones locales y las asociaciones católicas ${ }^{10}$.

A partir de estos datos pasamos a establecer una tipología de ateneos a través de las etapas definidas en el cuadro estadístico con el fin de concretar un fin fundamental de su identidad sociocultural: la formación de las clases populares - y menestrales - y la modernización política y cultural de la sociedad catalana ${ }^{11}$.

\section{Ateneos constituyentes (1836-1887)}

Los ateneos, de raíz británica e instructiva y de matriz profesional, popular y menestral aparecen en Catalunya de forma paralela y en contraposición a los casinos, de raíz italiana y recreativa y de matriz señorial y burguesa $^{12}$. Los ateneos - espacios recreativos, culturales e instructivos que procuraban influir en el nivel cultural de las clases populares-, a la vez establecían un campo de acción social conjunto junto a sociedades,

\footnotetext{
${ }^{9}$ Los datos en la BDACC, complementados con los que ofrece Solà, 1983 (a), 1994, 1998; Rodón, 1982. Arnabat y Ferré, 2015.

10 Ibídem.

11 Véase el modelo de análisis en el ya clásico Solà, 1978.

12 Zozaya, 2007 y 2015.
} 
coros y corales, círculos, bandas de música, mutuas y cooperativas. Citemos, pues, los ateneos más significativos de Catalunya con el fin de reseguir el período cronológico establecido y observar, nominalmente, concepciones ideológicas que los aglutinan.

A pesar de que los primeros documentos relacionados con el mundo ateneístico de que disponemos son unos estatutos del Ateneo Catalán redactados en 1836, el primer ateneo que se formó en Catalunya fue la Societat d'Amics de la Instrucció-Ateneu Mataroní el año 1854. Hasta 1887 le siguieron veintisiete ateneos en quince comarcas catalanas, habiendo jugado un papel fundamental en su difusión la ciudad de Barcelona y las ciudades medianas ${ }^{13}$. El objetivo de los ateneístas, tal y como se señalaba con motivo de la creación del Ateneu de Vilanova i la Geltrú (1877) era conseguir «el equilibrio en el desarrollo de los intereses morales y materiales» porque sin ello, «no hay paz, sosiego ni bienestar en los pueblos y naciones» ${ }^{14}$.

Cabe destacar que el movimiento ateneístico se desarrolló en paralelo al canto coral popular, difundido por el republicano federal Josep Anselm Clavé. El año 1867 ya funcionaban en Catalunya 106 corales y a finales de la década de los setenta del siglo XIX, el canto coral reunía a unos 40.000 obreros y campesinos en las comarcas catalanas. Este hecho no hacía otra cosa que definir la institución «ateneo» en el marco de relaciones con asociaciones afines ${ }^{15}$.

13 Mencionamos seguidamente los ateneos más notorios constituídos hasta 1887: Centre de Lectura de Reus (1859), Ateneu Català (1860), Centre de Lectura de Valls (1862), Ateneu Hortonenc (1864), Associació Ateneu Centre Democràtic i Progressista de Caldes de Montbui (1865), Ateneu de Sant Lluís Gonçaga de Barcelona (1866), Ateneu Instructiu de Banyoles (1869), Centre de Lectura de Montblanc (1870), Societat Cultural la Vicentina de Sant Vicenç dels Horts (1871), Ateneu Barcelonès (1872), Ateneu Agrícola de Sant Sadurní d'Anoia (1877), Ateneu de Vilanova (1877), Ateneu El Lauro de la Selva del Camp (1878), Ateneu Gracienc (1878), Ateneu Lliure de Barcelona (1878), Ateneu Catòlic de Valls (1879), Ateneu Lliure de Terrassa (1879), Ateneu Sabadellenc (1880), Ateneu Lliure del Llobregat de Sant Feliu de Llobregat (1881), Ateneu Constància de Barcelona (1881), Ateneu Científic i Literari de Rubí (1883), Ateneu Demòcrata Republicà de Granollers (1883), Ateneu Arenyenc d'Arenys de Mar (1884), Ateneu Literari i Recreatiu de Cornudella [de Montsant] (1884), Ateneu Banyolenc (1885), y Ateneu Catòlic de Sant Gervasi de Cassoles de Barcelona (1886). Vid: Arnabat y Ferré, 2015, p. 41-101.

14 Virella, 1977.

15 La relación entre ateneos y canto coral era muy estrecha, de manera que muchos ateneos tenían grupo coral y, en algunos casos, la creación de un grupo coral era el primer paso para la formación de una entidad cultural y/o recreativa. Esto es lo que sucedió, por 
De forma paralela al ateneísmo popular e interclasista orientado a la instrucción y la cultura, se fue configurando una red de casinos, predominantemente creados por las clases acomodadas y con fines recreativos y relacionales ${ }^{16}$.

Durante la década central del siglo XIX se formaron numerosas asociaciones que se movían entre el ateneo y el casino: círculos, sociedades, liceos, centros $^{17}$. A principios del siglo XX aparecieron las Casas del Pueblo socialistas y republicano-radicales que no dejan de ser ateneos di-

ejemplo, con la Societat Coral la Unió de Cornellà de Llobregat (1854); la Societat Coral Joventut Terrasenca (1858); la Societat Coral la Unió Vilanovina (1858) o la Societat Coral l'Esperança d'Arenys de Mar (1863). La primera sociedad coral catalana fue La Fraternitat (1850), derivada de la sociedad filarmónica L'Aurora, creada per Clavé en 1845, y denominada Euterpe desde 1857. Le siguieron la Societat Filarmònica Olotense (1845), Societat Filarmònica de Banyoles (1850), Coral Iris de Gràcia (1852), Societat Coral Erato de Figueres (1854), Societat Coral La Unió de Cornellà de Llobregat (1854), Societat Coral Juventut Terrassenca (1858), Societat Coral la Unió Vilanovina (1858), Coral Aroma Vallenca (1861), Orfeó Lleidetà (1861), Cor La Lira de Sant Just Desvern (1861), Societat Coral El Penedès de Vilafranca del Penedès (1862) o la Societat Coral l'Esperança de Arenys de Mar (1863). Fue, también, durante los años centrales del siglo XIX cuando se crearon las primeras bandas música en las comarcas del Ebro, como las de Alcanar (1845) y de Ulldecona (1870). Vid: Carbonell, 2000, 2007. Artís, 1980. Poblet, 1973. García Balañà, 1996, p. 103-137.

${ }^{16}$ Entre los primeros destacan el Casino de la Pobla de Segur (1828), Casino la Unión Guixolense (1840), Casino Barcelonés (1844), Casino del Centre de Cervera (1844), Casino Gerúndense (1845), Casino de Vic (1848), Casino de Girona (1848), Casino de Tortosa (1850), Casino Cerdà (1852), Casino Unió Comercial de Vilafranca del Penedès (1853), Casino de Amigos de Palafrugell (1853), Casino de Blanes (1854), Casino Menestral de Figuerenc (1856), Casino Llagostarenc (1856), Casino Figuerenc (1857), Casino Lloretenc (1858), Casino de Cadaqués (1858), Casino Palafrugense (1859), Casino del Comerç de Terrassa (1860). Arnabat y Ferré, 2015, p. 115132. Solà, 1993, p. 223-235. Santana, 2001, p. 221-236. Dos ejemplos en Ponce, 2008 y Quesada, 2014.

17 Como ejemplos: Societat Cultural i Recreativa La Concòrdia de Darnius (1846), Societat Teatral Banyolense (1850), Societat La Concòrdia de Agullana (1851), Societat El Círcol de Reus (1852), Foment Vilanoví (1853), el Círculo Olotense (1855), Passió d'Olesa de Montserrat (1855), Societat Recreativa de Santa Coloma de Cervelló (1856), Cercle Sabadellés (1856), Círculo Vallense (1856), Societat L'Amistat de Cadaqués (1857), Cercle Circ Ripollès (1857), Liceo Figuerenc (1858); Unió Vilanovina L'Acord i el Coro (1859) o el Cercle Liteari de Vic (1860). Así mismo, aparecen los centros morales e instructivos creados por la Iglesia católica, como la Pía Unión de Jóvenes devotos de san Luis Gonzaga de Barcelona (1851), los Llü̈sos de Gràcia (1855), el Centre Moral i Instructiu de Gràcia (1869), el Centre Social Catòlic de Terrassa (1878) o el Centre Moral $i$ Instructiu de Llorenç del Penedés (1897). Arnabat y Ferré, 2015, p. 41-171. Ver también Callahan, 2002. Winston, 1989. Garrido, 1986. 
rectamente ligados a sus respectivas culturas políticas: Casa del Poble Fraternitat Republicana de Amposta (1903), o las Casas del Pueblo del Perelló, de Sitges y de Mataró (1904) o de Maçanet de Cabrenys y de Blanes $(1905)^{18}$.

Las sedes de los ateneos contaban habitualmente con tres espacios básicos: el café, el salón de baile y/o teatro y la biblioteca ${ }^{19}$. La mayoría de las asociaciones culturales y recreativas creadas en Catalunya durante la segunda mitad del siglo XIX tenían como objetivos básicos la transmisión cultural, la educación popular y la gestión del ocio. En cuanto a la formación e instrucción se contemplaba, tanto la básica (alfabetización), como la instrumental/profesional/específica (conocimientos científicos, literarios, filológicos, artísticos, profesionales).

Entre las aportaciones culturales de los ateneos debemos destacar la introducción en el país de las principales corrientes de pensamiento europeo y la culturalización, más allá de la instrucción, de las clases populares ${ }^{20}$. Elementos imprescindibles para la creación de ciudadanos dotados de capacidad autónoma para ejercer sus derechos civiles y políticos. Es por esta razón que un espacio fundamental de los centros de lectura y de los ateneos eran las bibliotecas y gabinetes de lectura que permitían el acceso a fondos de consulta y de lectura. Así lo manifestaba el presidente del Centre de Lectura de Reus, Eugeni Mata Miarons, en un artículo valorativo con motivo de la presentación del primer catálogo bibliográfico completo del Centre de Lectura de Reus (1897): «fundar en la instrucción el bienestar y mejora de todas las clases sociales, por depender de ella muy principalmente el progreso y la civilización de los pueblos» ${ }^{21}$. Veamos, en consecuencia, tres tipologías de asociacionismo ateneísta que sirven para concretar la relación entre sociabilidad, formación e identificación con una ideología política determinada.

18 Moral, 2014, p. 123-144. Luis y Arias, 1979.

19 La mayoría fueron levantados por los propios socios y una minoría fueron diseñados por arquitectos reconocidos, llegando hasta hoy verdaderas joyas del patrimonio arquitectónico y cultural: Centre de Lectura de Reus, Ateneu Barcelonès, Ateneu Igualadí de la classe obrera, Ateneu de Tàrrega, Centre Moral i Instructiu de Gràcia, Cooperativa Obrera La Fraternitat de la Barceloneta, Odeón de Canet de Mar, Sociedad de Fomento Voluntario de la Villa de Gracia, Casino de Vic o Casino Llagosterenc.

${ }^{20}$ Comas/Oliva [coords.], 2011.

21 Mata, 1897. Sobre las bibliotecas Populares en Catalunya ver Comas, 2001 y 2017. 
Centre de Lectura de Reus ${ }^{22}$

El Centre de Lectura de Reus fue creado a partir de la iniciativa de obreros y menestrales el año 1859. Uno de sus referentes fundacionales fue el republicano posibilista Josep Güell Mercader, quien definió con exactitud los objetivos de la nueva asociación: «Centre, en fi, d'ensenyança $i$ d'educació populars obert a les idees de progrés, però sense exclusivismes de cap mena» ${ }^{23}$. Unos objetivos que, después de un año de funcionamiento, eran reafirmados en la Memoria de la entidad: instrucción, moralidad y buenas costumbres. A través del Centre las principales corrientes del pensamiento europeo de la época: el positivismo, el naturalismo, el romanticismo o el historicismo, recogidos en sus publicaciones: el periódico El Porvenir (1860) y la revista El Eco del Centro de Lectura (noviembre de 1859 a junio de 1860 y enero-noviembre de $1862)^{24}$. Durante sus primeros diez años de vida se formó la sección coral $(1860)^{25}$ y se construyeron unos jardines musicales - L'Euterpe- (1862) y el salón de baile (1862).

\section{Ateneu Barcelonès ${ }^{26}$}

Como ejemplo de ateneo burgués y profesional tenemos el Ateneu Barcelonès. La clase dirigente catalana, la burguesía, también recurrió al ateneísmo para configurar su laboratorio de ideas donde pensadores, profesionales y técnicos elaborasen un programa que unificase y cohesionase la sociedad catalana en el marco de sus intereses de clase. En definitiva, sustentar el dominio económico y político, sobre la hegemonía social y cultural, mediante la constitución de un bloque de poder conservador.

El año 1844 se fundó el Casino Barcelonés y el año 1860 se creó el Ateneo Catalán. Esta entidad se dirigía a la reunión de la intelectualidad y de los sectores productivos: «faltaba en esta ciudad un centro que, al mismo tiempo que punto de reunión de las varias clases sociales, de lectura y de agradable y útil conversación, pudiera discutir y acordar lo que

\footnotetext{
22 Anguera, 1977.

23 Güell y Mercader, 1900, p. 126.

24 Ferré, 2011.

25 Gort y Gomis, 1994, p. 10-11.

26 Casassas, 1986. Sans Orenga, 1983.
} 
pudiera ser favorable [...] e interesar a la ciencia, a las letras y a las artes.» ${ }^{27}$ Cuatro años más tarde se formó el Círculo Mercantil (1864) patrocinado por la Lonja para promover la reflexión sobre aspectos económicos de la ciudad y de la región. Tres propuestas asociativas con fines parecidos que acabaron fusionándose. El Casino Barcelonés y el Círculo Mercantil constituyeron en 1869 el Centro Mercantil Barcelonés y éste y el Ateneo Catalán se fusionaron para crear el Ateneu Barcelonès (1872), que eligió como presidente al jurista liberal conservador Manuel Duran i Bas.

La vida del Ateneu Barcelonès durante la década inicial estuvo marcada por fuertes tensiones entre los socios, que representaban diversas opciones dentro de la clase dominante barcelonesa: monárquicos, conservadores y progresistas. Como respuesta intelectual-política se creó el Ateneu Lliure de Catalunya - a partir del Ateneu Lliure de Barcelona - y al cual acudió la intelectualidad republicana liderada por el médico Joan Giné Partagàs y el político Valentí Almirall.

\section{Ateneu Igualadí de la Classe Obrera ${ }^{28}$}

Si las clases acomodadas, las clases medias y los sectores menestrales catalanes constituyeron sus propios ateneos, no se quedaron atrás los obreros y, a lo largo de la segunda mitad del ochocientos se constituyeron diecisiete ateneos obreros y menestrales ${ }^{29}$. Una de las entidades más representativas de estos centros fue el Ateneu Igualadí de la Classe Obrera (1863), fundado por cuatro tejedores - Antoni Carner, Antoni Vila, Ferran Salat y Josep Estany - y nueve trabajadores más, con el fin de formar a la clase obrera y disponer de un espacio de sociabilidad para

27 Casassas, 1986, p. 20 describe ese proceso como «la movilización de los cuadros».

28 Riba, 1988.

29 Ateneu Català de la Classe Obrera de Barcelona (1861), Ateneu Igualadí de la Classe Obrera (1863), Ateneu Tarragoní de la Classe Obrera (1863), Ateneu de la Classe Obrera de Sants (1864), Ateneu Català de la Classe Obrera de Manlleu (1864), Ateneu Obrer Manresà Tarragona (1864), Ateneu Obrer de Vilanova [i la Geltrú] (1879), Ateneu Mataroní de la Classe Obrera (1880), Ateneu Obrer de Sabadell (1880), Ateneu Obrer Barcelonès (1881), Ateneu Centellenc de la Classe Obrera (1882), Ateneu Obrer de Barcelona (1882), Ateneu Vilassanès de la Classe Obrera (1883), Ateneu Obrer de Badalona (1884), Ateneu Obrer de Vilafranca [del Penedès] (1885), Ateneu Obrer de Sant Andreu del Palomar (1885). Vid: Arnabat y Ferré, 2015, p. 41-150. 
los trabajadores de la industriosa ciudad de Igualada. Su referente era el Ateneu Català de la Classe Obrera de Barcelona, fundado dos años antes y sus primeros pasos se enmarcaron en el progresismo y el republicanismo.

Durante su primer año se inscribieron 400 socios numerarios y 100 de protectores. En el segundo año creó el Cor Orfeó. Entre 1866 y 1873 la entidad publicó una serie anual de memorias y construyó el primer teatro de aficionados, aunque la crisis industrial que padecía el país en 1866-1867 redujo el número de socios numerarios a 253 y el de protectores a 85. El año 1873, en el marco de la tercera guerra dinástica, los carlistas ocuparon la ciudad e incendiaron el local del Ateneu, aunque su actividad continuó y el año 1876 se organizó la sociedad obrera de los sazonadores y la coral La Llàntia. Finalmente, el año 1878, se inauguró el nuevo local que contaba con un espacioso teatro y donde reside la entidad desde entonces hasta la actualidad y. A partir de 1880 y hasta 1887 se organizaron certámenes científicos-literarios anuales, la biblioteca contaba con 500 volúmenes y se publicaba El Ateneo: revista mensual del Ateneo Igualadino de la Clase Obrera (julio de 1885 a agosto de 1898).

Entre 1836 y 1886 se crearon 384 ateneos o centros similares en 34 de las 41 comarcas catalanas, situadas preferentemente en el litoral y el prelitoral (ver mapa 1).

Según esta cartografía, la concentración asociativa - basándonos en la ratio a partir del $25 \%$ de implantación - se define en torno a la región litoral-prelitoral. Cabe destacar que la localización sociabilista formal, y en concreto, la ateneísta, define implantación en regiones donde se ha definido una base asociativa política - L'Empordà, L'Anoia y El Bages-, o agraria -El Penedès - . Como hipótesis derivada de este mapa planteamos la relación entre dinámica asociativa y especialización productiva.

Desde el inicio del movimiento ateneístico Catalunya hegemonizó - tanto desde el punto de vista numérico absoluto, como porcentual respecto de la población (densidad asociativa) - en cierto sentido, la dinámica asociativa en el estado español ${ }^{30}$.

${ }^{30}$ En una futura investigación hay que comparar tipologías asociativas de acuerdo a cada formación sociohistórica. Sólo así podremos tener veraz conocimiento de sincronías y disincronías, y fundamentalmente de la relación entre densidad asociativa y sus causas, no necesariamente engarzadas con un casi determinismo economicista. 


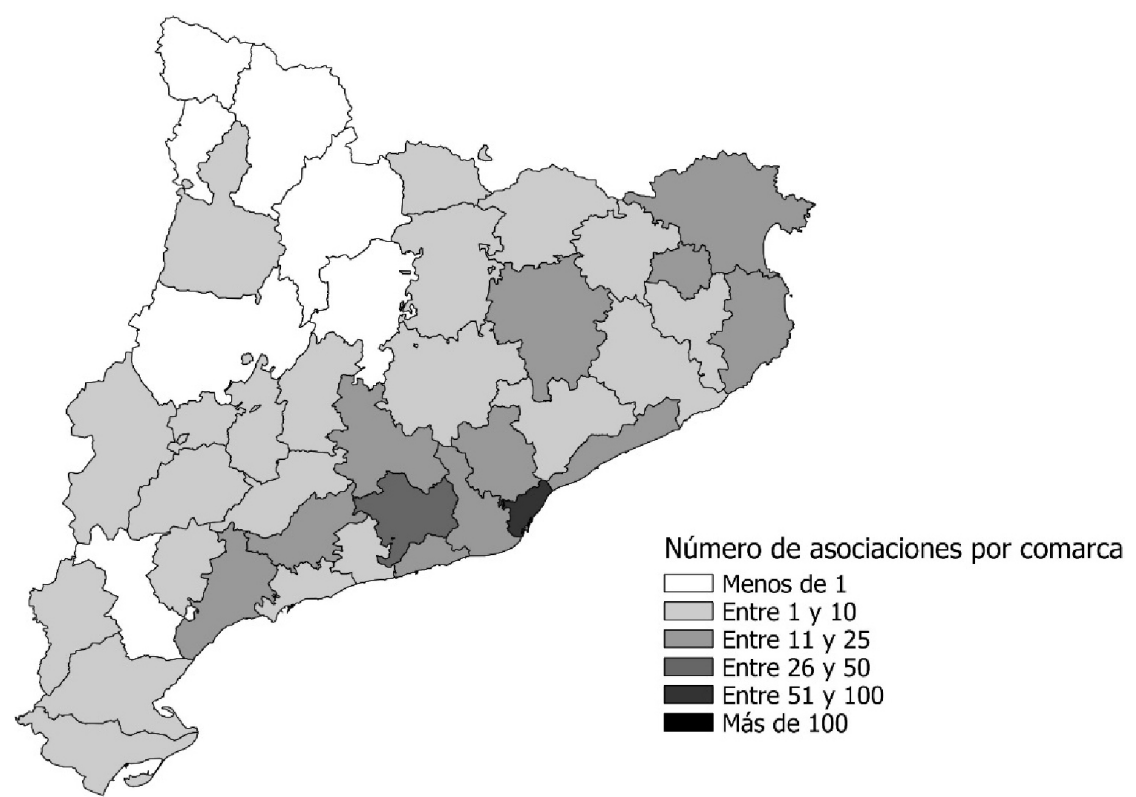

\section{Mapa 1}

Asociaciones culturales y recreativas en Catalunya, 1830-1886

Fuente: Elaboración propia a partir de la BDACC del grupo de investigación ISOCAC-URV.

En un recuento realizado por el Ministerio de la Gobernación el año 1887 se documentaron 3.108 asociaciones en el estado español, el 59\% de las cuales eran recreativas o instructivas: $1.061^{31}$. De estas, una de cada tres $(34 \%)$, residía en Catalunya que contaba con el $11 \%$ de la población, lo que daba una densidad asociativa de 1.731 habitantes por asociación, mientras que la media estatal era de 5.684. El criterio porcentual, representado en el mapa 2, es la correlación existente entre su incremento cromático y mayor densidad asociativa por habitante (menor número de habitantes por asociación); mientras que el decremento gráfico revela una

31 Archivo Histórico Nacional. Ministerio de Gobernación. Dirección General de Seguridad, FC_M.'_Interior. Legajo 575, exp. 1. 
menor densidad asociativa por habitante (mayor número de habitantes por asociación) $)^{32}$.

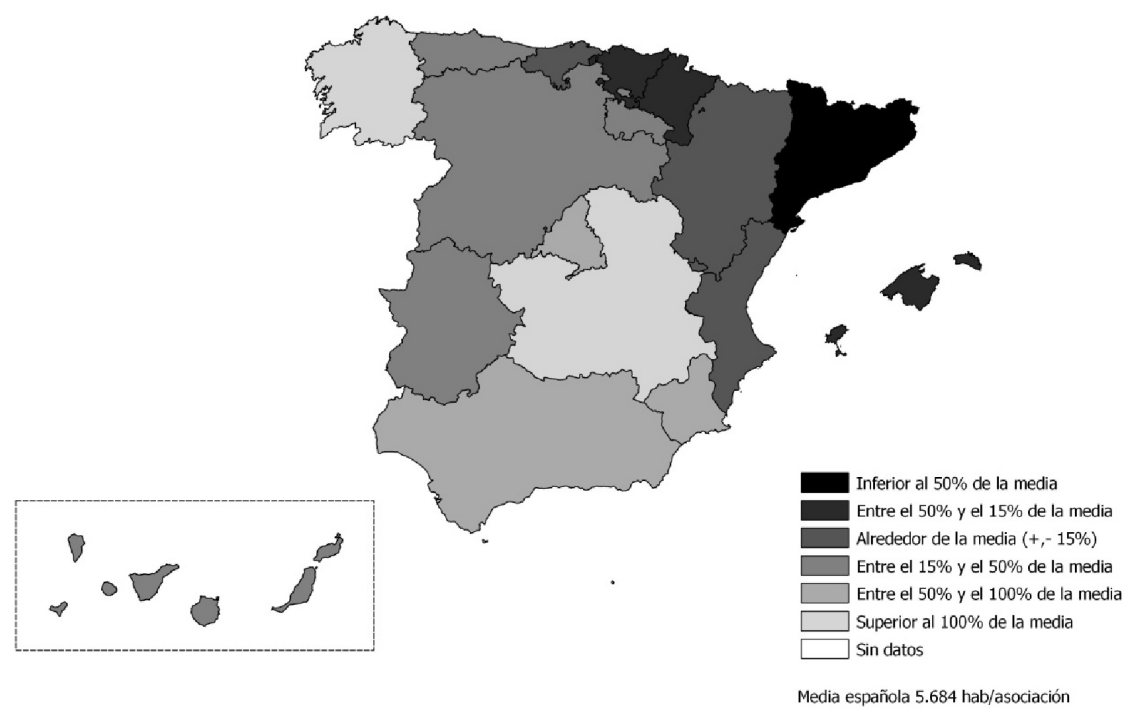

\section{Mapa 2}

Densidad asociativa territorial: habitantes por asociación, 1887

Fuente: Elaboración propia a partir del «Resumen de las Sociedades de todas clases existentes en España en el día 1. ${ }^{\circ}$ de enero de 1887, con expresión de su objeto según los datos facilitados a esta Dirección General. Clasificación y objeto». AHN. FC_M.'_Interior. Legajo 575, expediente 1.

Como puede apreciarse en el mapa 2, las más altas densidades asociativas - superiores a la media estatal - se dan en Catalunya, Islas Baleares, Navarra-País Vasco. También cabe destacar la densidad asociativa en el País Valenciano, Cantabria y Aragón ${ }^{33}$. De la comparación entre ambos mapas se puede extraer la hipótesis de que, en esa etapa, la densidad asociativa corre en paralelo a la gradación del proceso de implantación de las relaciones sociales capitalistas mediante la industrialización periurbana y

32 Arnabat, 2016.

33 Solà, 1983(a), 1994, 1998. Rodón, 1982. Duch, Arnabat y Ferré, 2015. Serra y Company (Coords.), 2001, Cucó, 1991, Canal et al., 2003. 
la creciente especialización y comercialización agraria. La densidad asociativa en el estado español está en función de ese desarrollo socioeconómico $-\mathrm{y}$ de la identidad cultural - que muestra sus contradicciones con los modelos de sociabilidad adecuados a bloques sociales de poder y sus culturas políticas y formas de resistencia cultural.

\section{Consolidación territorial (1887-1900)}

Entre 1887 y 1900, el ateneísmo en Catalunya consolidó la base territorial y social ${ }^{34}$. Como podemos ver en el mapa 3 -siguiendo la lógica explicativa efectuada para el mapa $1-$, fue en las comarcas litorales y pre litorales donde se crearon más ateneos entre 1887 y 1900: Barcelonès, Alt Penedès, Maresme, Alt Empordà, Garraf, Baix Llobregat, Baix Penedès, Tarragonès y Baix Camp ${ }^{35}$. Pero el ateneísmo penetró también, aunque de manera menos densa, en las comarcas del interior: Alt Camp, L'Anoia, El Bages, Vallès Occidental y Oriental, Osona y Priorat. Lo cual significa la ausencia de un modelo - mecánico - general para todos los casos y sí, en cambio, la concreción de vías asociativas muy dependientes de la dinámica de la vida comunitaria global. Cada periferia deviene su propio centro de sociabilidad, lo que puede explicar una lógica de desarrollo policéntrico de implantación.

Nuestros cálculos indican que, en este período, estarían funcionando un total de 500 ateneos, casinos y centros: 385 de nuevos y 115 de antiguos, repartidos en 33 comarcas (mapa 3$)^{36}$. En general, las comarcas con un índice más alto de asociacionismo cultural y recreativo, se caracterizaban por una creciente especialización y comercialización agrícola y/o por el desarrollo industrial, y por una creciente urbanización de su población.

${ }^{34}$ Nos sirven de muestra: el Ateneu Ripollès (1888), Ateneu de Borrassà (1890), Ateneu Català de Sallent (1890), Ateneu Calderí de la Classe Obrera de Caldes de Montbui (1891), Ateneu la Unió de Santa Coloma de Cervelló (1892), Ateneu Instructiu de Cornellà [de Llobregat] (1893), Ateneu Santboià de Sant Boi de Llobregat (1893), Ateneu de Sant Joan d'Espí (1895). Hay que destacar los Ateneos que, implantados en ámbitos rurales, difundían la cultura republicana: Ateneu Republicà Federal d'Instrucció i Esplai de Olesa de Montserrat (1895) y Ateneu Sallentí de la Unió Republicana (1896). Como monografías ilustrativas de estudio asociativo local remitimos a Cao Costoya, 2015; Anguera, 1999 y las síntesis recogidas en Duch, Arnabat y Ferré, 2015.

35 Arnabat y Ferré, 2015, p. 41-210.

${ }^{36}$ Los estudios locales realizados en distintos municipios de Catalunya, nos muestran que aproximadamente un $30 \%$ de las entidades de un período siguen activas en el siguiente. 


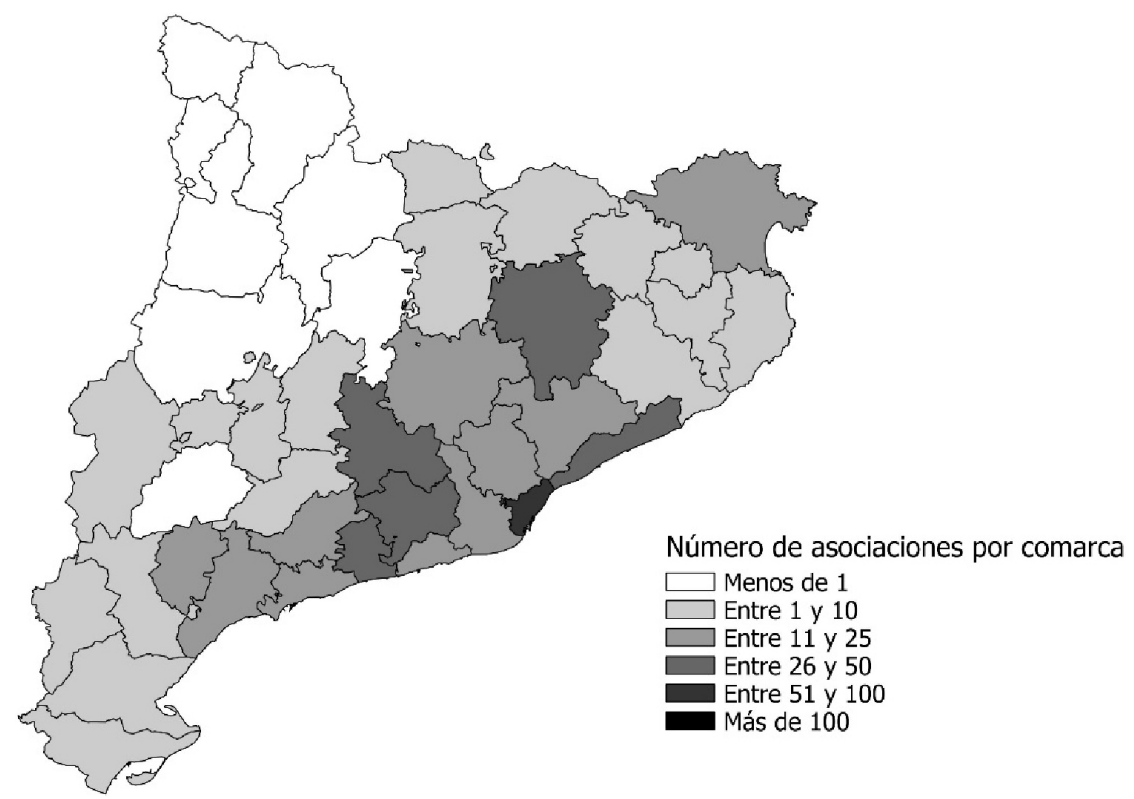

Mapa 3

Asociaciones culturales y recreativas en Catalunya, 1887-1900

Fuente: Elaboración propia a partir de la BDACC del grupo de investigación ISOCAC-URV

Según el estudio realizado por el Grupo de Estudios de Asociacionismo y Sociabilidad de la Universidad de Castilla-La Mancha, en 1895 el asociacionismo catalán representaba el $24 \%$ en el estado español y, en consecuencia, seguía encabezando la densidad asociativa ${ }^{37}$.

En el cambio de siglo y durante el primer tercio del siglo Xx, la sociedad catalana fue adoptando nuevas formas de sociabilidad acorde con la difusión de medios de comunicación de masas y el impulso de nuevas sociedades. Ello supuso un salto cuantitativo y transformación cualitativa, ya que, como señala Jordi Casassas para el Ateneu Barcelonès, el período 1860-1906 marca un «antes» y un «después», delimitados por un relevo

37 GEAS, 1998, p. 60-79. 
generacional que permitió la adopción de nuevas ideas. Configurándose como la institución que representaba la formación de una plataforma de manifestación de los «intelectuales orgánicos» de la burguesía restauracionista catalana y, en consecuencia, de corrientes estéticas e ideológicas como el noucentisme ${ }^{38}$.

\section{Hacia la expansión (1901-1920)}

Entre 1901 y 1920 se constituyen 512 nuevos ateneos, a los que debemos añadir 150 que permanecen del período anterior, sumando un total de 662 repartidos por 37 comarcas, como podemos ver en el mapa 4 . Se-

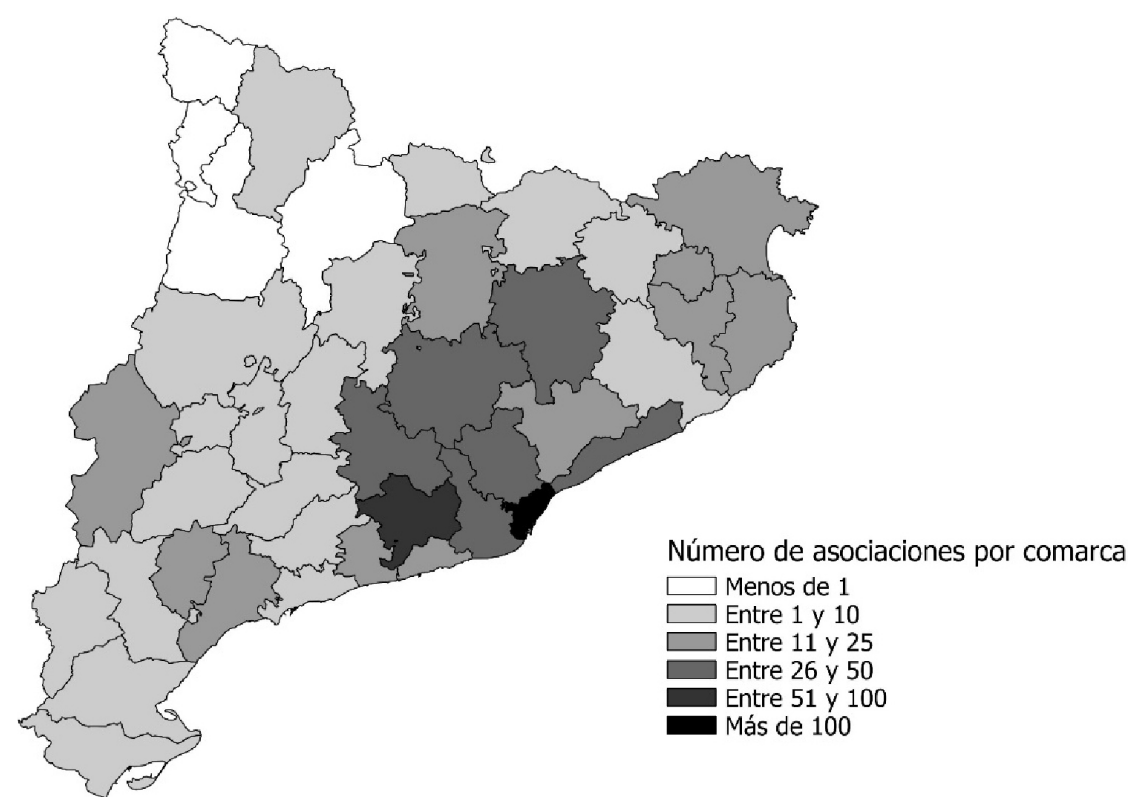

\section{Mapa 4}

Asociaciones culturales y recreativas en Catalunya, 1901-1920

Fuente: Elaboración propia a partir de la BDACC del grupo de investigación ISOCAC-URV.

38 Casassas, 1986, p. 85-87. 
gún los datos del Instituto de Reformas Sociales de 1904, Catalunya sigue encabezando el movimiento asociativo peninsular con 2.239 entidades de un total de 5.609 registradas oficialmente, un $40 \%$. Siendo también la que registra una densidad asociativa más alta, con 931 habitantes por asociación, frente a los 3.557 de la media estatal (ver mapa 5) ${ }^{39}$.

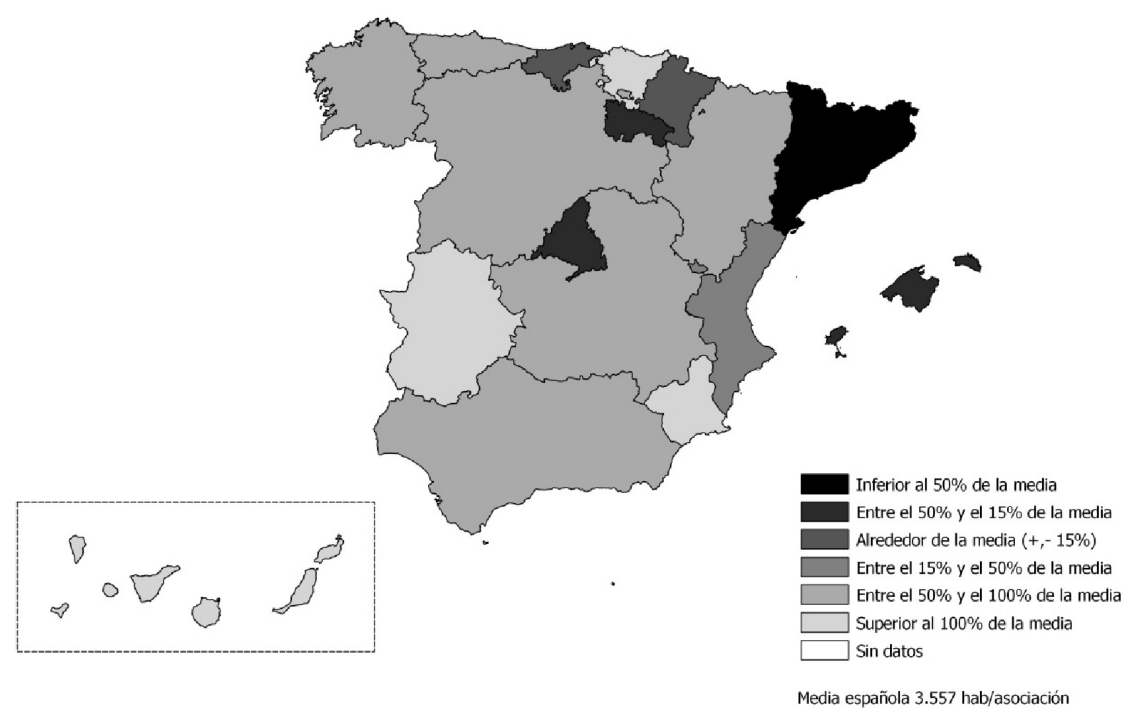

Mapa 5

Densidad territorial del asociacionismo obrero, 1904

Fuente: Elaboración propia a partir de Instituto de Reformas Sociales, Estadística de la Asociación obrera en 1. de noviembre de 1904, Madrid, 1907.

En el censo asociativo realizado el año 1916, Catalunya seguía siendo el país donde se concentraba la mayor parte del asociacionismo del estado español, aunque se había reducido el porcentaje sobre el total hasta el $15 \%$. A pesar de ello, continuaba siendo el territorio histórico con mayor densidad asociativa con 564 habitantes por asociación, frente a los 1.148

39 Instituto de Reformas Sociales, Estadística de la Asociación obrera, 1904 (1907). 
de la media estatal, seguida de las Islas Baleares, el País Valenciano, La Rioja, el País Vasco y Cantabria (mapa 6) ${ }^{40}$.

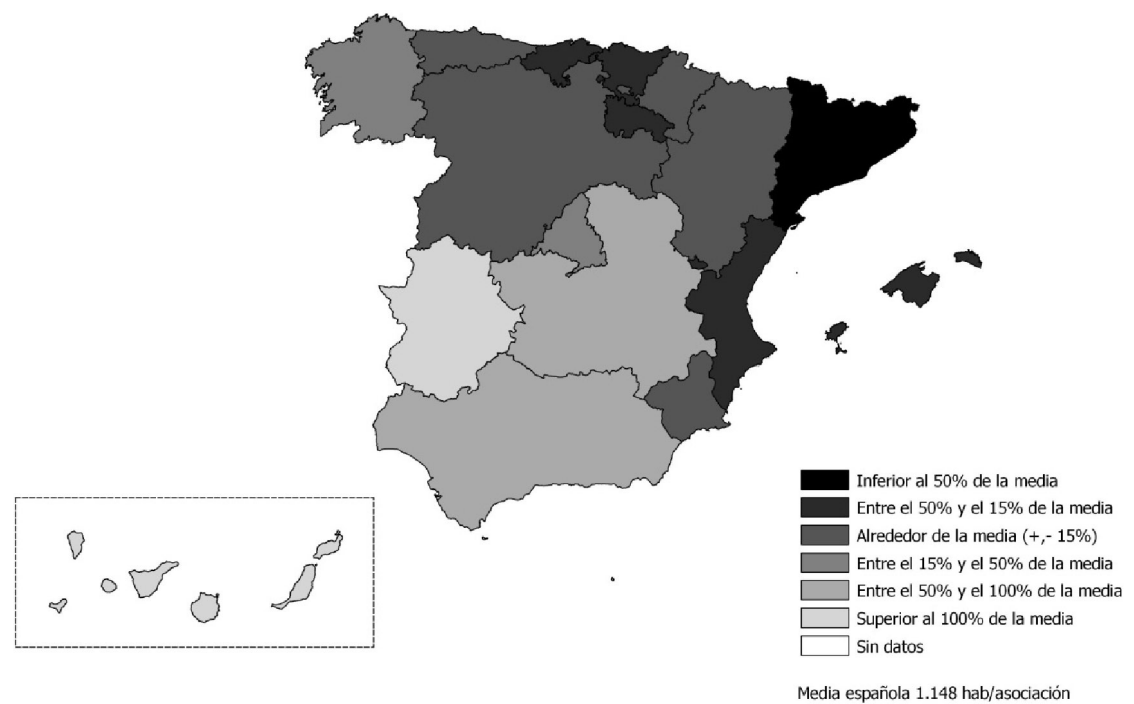

\section{Mapa 6}

Densidad territorial del asociacionismo sociabilista profesional y no profesional (1916)

Fuente: Elaboración propia a partir del Instituto de Reformas Sociales, Estadística de asociaciones... En 30 de junio de 1916 (1917). 1917.

Durante este período, el ateneísmo - asociado comúnmente con culturas políticas hegemónicas, como fue el catalanismo republicano autodeterminista, el anarquismo y el emergente frentepopulismo- se hace mayor de edad mediante su expansión territorial, la creación de nuevos centros y los nuevos campos de actividad. Todo ello en el marco de una creciente politización, hecho significativo en el Ateneu Enciclopèdic Popular.

40 Instituto de Reformas Sociales, Estadística de asociaciones, 1916 (1917). 
Ateneu Enciclopèdic Popular ${ }^{41}$

El Ateneu Enciclopèdic Popular (AEP) nace en el contexto de la huelga general de febrero de 1902 impulsada por el abogado sindicalista Francesc Layret - que en 1920 caería asesinado por pistoleros de la patronal-, el albañil Josep Tubau y el cooperativista Eladi Gardó quienes a la vez contaron con el apoyo de dieciocho personas más de dedicaciones profesionales diversas. Su referente intelectual fue el Ateneu Català de la Classe Obrera $(1861)^{42}$. Mientras que su modelo internacional fue el de la universidad popular fundada el 1888 por el intelectual francés Anatole France. Dicha institución se organizaba en secciones y ámbitos de reunión y de debate, además de contar con una biblioteca, un laboratorio y una escuela normal de educadores populares ${ }^{43}$.

L'Enciclopèdic comenzó su trayectoria el año 1903 en el local de la Associació dels Cors de Clavé. Posteriormente cambió de sede en diversas ocasiones hasta que el año 1906 consiguió un local definitivo, a la vez que implantaba clases de idiomas (francés) y de ciencias. Organizaba cursos y actividades para socializar la cultura obrera. Aunque, a diferencia del Ateneu Igualadí de la clase obrera, no estableció un ámbito específico dirigido a las escuelas. A partir de 1906 el Enciclopèdic estableció campañas sobre temáticas sociales y culturales que no debían tener como finalidad el ocio. En este contexto formativo sus estatutos proponían: «difundir los conocimientos científicos en sus diversos órdenes haciendo que penetren en todas las clases sociales y a la sociedad obrera en particular.»

El funcionamiento pedagógico del AEP incorporó el 1910 la Fundació Horaciana d'Ensenyança dirigida por el geógrafo i pedagogo Pau Vila. A partir del curso 1913-1914 la asociación inició clases de inglés, de gramática, de escritura literaria, de taquigrafía, de teneduría de libros, de dibujo lineal. Y tenía secciones de: excursionismo, ciencias, sociología, literatura y bellas artes, geografía e historia, artes industriales, esperanto), gimnasia, deportes, fotografía, topografía, rapsodia. Entre 1916 y 1936 se desarrolló una sección de pedagogía que organizó unas conversaciones dirigidas a los socios jóvenes de la entidad.

Entre 1906 y 1923 - antes de ser clausurado por el Directorio de Primo de Rivera- el Enciclopèdic definió y expandió su modelo forma-

\footnotetext{
41 Solà, 1978 y Aisa, 2000.

42 El proceso constituyente del AEP en Aisa, 2000, p. 39-48.

43 Leduc, 2004.
} 
tivo, lo cual contó con la implicación fundacional de primera hora de políticos obreristas como Francesc Layret. Durante estas dos décadas el AEP alcanzó la cifra de 20.000 afiliados e innumerables secciones «encaminades a fomentar el col-lectivisme de les persones» ${ }^{44}$.

Fue en este contexto de emergencia territorial ateneísta que se constituyó la Unió d'Ateneus Obrers de Catalunya (1906) y se celebraron dos congresos federativos para hacer un balance de la orientación, actividades y proyecciones en el área asociativa: Reus (1911) y Vilanova i la Geltrú (1912).

I Congrés d'Ateneus (Reus, 1911)

El Primer Congrés regional d'Ateneus y Associacions de Cultura fue organizado por el Centre de Lectura de Reus los días 15, 16 y 17 de abril de 1911, coincidiendo con la constitución en el Centre de la Institució Popular de Cultura, una sección que tenía objetivos intelectuales coincidentes con el asociacionismo cultural. El objetivo del Primer Congrés era, según establecía su Reglamento, estudiar las bases, los fines y los medios «que deu emplear l'Associació lliure de caràcter cultural pera satisfer la seva finalitat: divulgar y enaltir l'instrucció y l'educació, y consegüentment ennoblir la vida y l'esperit del poble». Se trataba, básicamente, de construir una estructura cultural contrapuesta a la política oficialista. A la vez que debía facilitar una socialización que, según el escritor Joan Ferraté Gili, favoreciese «la fraternitat, lo contacte y l'apropament que ha d'existir entre aquestos ateneus y entre aquestes associacions» ${ }^{45}$.

El presidente del Primer Congrés d'Ateneus fue el político republicano Pere Coromines Muntanya y el debate se organizó en dieciséis secciones. Los temas tratados en el Congrés formaban parte de los más diversos ámbitos del saber humanístico, político, sociológico, médico, estético, biblioteconómico, asociativo, pedagógico. Nos pueden servir de ejemplo de ello diversas conferencias pronunciadas por intelectuales y profesionales: «Los Ateneos obreros y la Economía Social», «Aspecto económico de los ateneos», «L'actualitat creadora com á norma de l'ensenyança», «Norma de l'associació de cultura pera desenrotllar y de-

44 «Manifest de l'Ateneu Enciclopèdic», 2007, p. 5-6.

45 Ferraté, «Congressisme», 1911. 
purar la receptivitat y sentit artístic del poble», «Missió idealista de les biblioteques populars», «Medios que pueden poner en práctica los Ateneos y sociedades de Cultura para coadyuvar á la educación integral de la clase obrera», «L'Ateneu afavorint la capacitació política dels ciutadans» o «l'Associació lliure a la democràcia» ${ }^{46}$.

Una de las conferencias que tuvo especial repercusión fue la del socialista Josep Recasens i Mercadé - socio del Centre de Lectura y miembro de la Sección de Estudios Políticos y Sociales - que con el título «L'esperit associacionista preparant el col·lectivisme», destacó que los ateneos debían estudiar la cuestión social y apoyar «l'acció del proletariat, en la seva missió d'organisar-se econòmica i políticament, pera implantar el colectivisme i conseguir, amb ell, el perfeccionament de tots els homes.» ${ }^{47}$ No es extraño si tenemos en cuenta que, como hemos señalado, el ateneismo se movía a principios del siglo XX entre las culturas políticas del republicanismo, el catalanismo, el anarquismo y el socialismo que hacían de la formación - intelectual y laboral - y de la cultura las palancas decisivas de la emancipación individual y colectiva ${ }^{48}$. Una acción cultural comunitaria que tenía en las bibliotecas populares un objetivo destacado.

II Congrés d'Ateneus (Vilanova i la Geltrú, 1912)

Los días 25, 26 y 27 de mayo de 1912 se celebró en Vilanova i la Geltrú y organizado por el Ateneu Vilanoví el II Congrés d'Ateneus i Societats de Cultura, que contó con la participación de 1.475 congresistas que representaban a 138 asociaciones. Según establecía el Reglamento del Segon Congrés estaban llamadas a participar en él todas las asociaciones culturales de Catalunya y «todos los que consideren la educación y la instrucción como el elemento más poderoso del progreso de los pueblos.» Formaban parte del Comité Ejecutivo intelectuales y profesionales de prestigio como Leopold Crusat Prats, Francesc Suñé Bolet, Joan Ventosa i Roig, Pau Vila o Eduard Fontserè,

Sus objetivos eran continuar los trabajos iniciados en el Primer Congrés. Las conferencias y debates se organizaron en diez comisiones: pedagogía, educación física, bibliotecas, ciencias físicas, químicas y na-

\footnotetext{
46 Arnabat y Ferré, 2015, p. 214-215.

47 Recasens, 1911, p. 154-155.

48 Bosch, 1991(a), p. 141.
} 
turales, estudios políticos, económicos y sociales, estudios mercantiles, cultura agrícola, cultura técnica y arte industrial, vida artística y excursionismo ${ }^{49}$.

Los diversos temas tratados ocupaban el espectro de las ciencias sociales y del ámbito productivo: orientaciones de las Sociedades económicas, la educación política y social del pueblo mediante los ateneos y la instrucción profesional y el contrato de aprendizaje, las orientaciones económicas de las entidades culturales y la forma de suplir les deficiencias de la enseñanza oficial, la divulgación de la geografía como base de cultura, la divulgación de la economía política como base de la cultura comercial y manera de materializarla para las entidades culturales, ventajas de la enseñanza mercantil para mujeres, actividades que podían realizar las entidades culturales, difusión de las nuevas técnicas vitivinícolas y de los modernos conocimientos enológicos, los ateneos como divulgadores de las experiencias personales de los campesinos, el papel de las sociedades culturales en la difusión de los medios para combatir las plagas naturales, la función de los ateneos rurales en la cultura y enseñanza agraria, la instrucción literaria y la instrucción técnica, la armonía entre les acciones oficiales y particulares en favor de la enseñanza técnica, la enseñanza profesional en las ciudades industriales, las bases morales y/o técnicas para la prosperidad de la industria de tejidos y la industria catalana, las escuelas de formación profesional como ampliación de la formación primaria a favor de les clases obreras ${ }^{50}$.

Con todo, las diversas culturas políticas que había detrás de los ateneos y la politización creciente de estos, dificultaron enormemente el establecimiento de unas pautas de actuación comunes. En el mundo ateneístico catalán había ateneos monárquicos y republicanos, católicos y aconfesionales, carlistas y liberales, anarquistas y socialistas, burgueses, interclasistas y obreros. De manera que las conclusiones generales consensuadas fueron pocas y con escasa proyección, ya que la coyuntura política hizo que las propuestas más atrevidas fuesen dejadas de lado por falta de consenso. La pugna entre intereses políticos y los sectores sociales que potenciaban a los ateneos evidenció la imposibilidad de una unidad de acción cultural. Además, se desestimó la posibilidad de hacer un III Congrés en Badalona, tal y como estaba previsto.

\footnotetext{
49 Segon congrés regional d'Ateneus $i$ Societats de Cultura, 1912, p. 8-10.

50 Arnabat y Ferré, 2015, p. 221.
} 
Las tensiones y los conflictos políticos, económicos, sociales y culturales durante el primer tercio del siglo Xx rompieron la unidad del movimiento ateneístico, aunque, unos años más tarde, la obra cultural de la Mancomunitat de Catalunya contribuyó a la difusión de los acuerdos del Segon Congrés d'Ateneus de Catalunya. Y el año 1936 se federaron las agrupaciones corales constituyendo la Federació Euterpense de Cors $i$ Orfeons de Clavé, para mantener vivo el recuerdo del maestro y el lema fundacional de los coros de Clavé: Progrés, Virtut, Amor.

Fue durante el último cuarto del siglo XIX y el primer tercio del siglo Xx cuando el asociacionismo ateneísta recabó entre sus objetivos, y práctica, cuestiones culturales - económicas y sociales - que acabaron por definir la porosidad urbana en el ámbito rural. Es decir, cabía tratar de cambios técnicos y organizativos en la producción agraria e industrial y, a la vez, codificarlos en clave de democratización cultural hacia espectros sociales cada vez más amplios. En cierto modo era la respuesta de la sociedad civil ante las limitaciones e inoperancia educativa y cultural del estado oligárquico español.

Durante las primeras décadas del siglo xx el mundo asociativo interclasista y popular se irá politizando y polarizando, de forma paralela a como lo hará la sociedad catalana, atravesada por conflictos políticos estructurales (contraposición de intereses de clase i de modelo de organización política territorial), culturales (católicos-monárquicos y anticlericales/laicos-republicanos) y socioeconómicos (propietarios y agricultores y trabajadores).

\section{Una expansión politizada (1921-1936)}

Durante el período 1921-1936 siguió la expansión ateneística, creándose 465 nuevas entidades, a las que se añadirían 199 que continuarían del período anterior, sumando un total de 664 asociaciones culturales y/o recreativas activas. Con todo, en esta coyuntura - Dictadura de Primo de Rivera (1923-1930) - el movimiento ateneísta relacionado con el catalanismo y el anarquismo vivió una época de represión. Nos sirven de ejemplo la clausura del Centre Autonomista de Dependents del Comerç i de la Indústria (CADCI) (1903), del Ateneu Barcelona Vella o del Ateneu Nacionalista del districte $V^{51}$. Queremos decir con ello que el concepto «expan-

${ }^{51}$ Roig, 1992, p. 527-528. 
sión» es concebido a partir de las contradicciones políticas reales (crisis de legitimidad) del estado español en el marco definido en este epígrafe.

En el mapa 7 podemos ver como el ateneísmo está sólidamente implantado en 40 comarcas, destacando el peso creciente de las comarcas del interior.

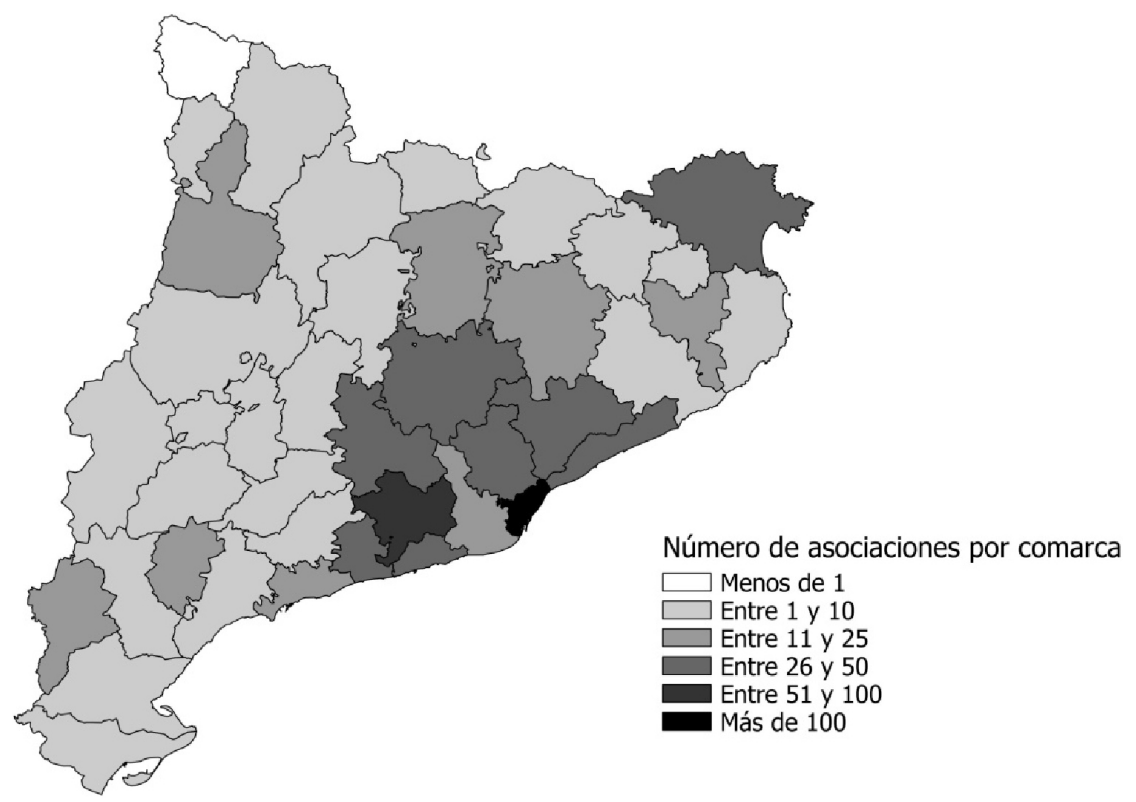

Mapa 7

Asociaciones culturales y recreativas en Catalunya, 1921-1936

Fuente: Elaboración propia a partir de la BDACC del grupo de investigación ISOCAC-URV

En el mapa 8 podemos observar que, durante este período, las comarcas del Garraf, Alt Penedès, L'Anoia, Baix Penedés, Priorat, Terra Alta y Pallars Jussà, son las que registran una alta densidad asociativa cultural y/o recreativa. Seguidas del Maresme, Vallès Oriental, Bages, Berguedà, Alt Empordà, Alta Ribagorça y Ribera d'Ebre. Todas ellas por encima de la media catalana. La mayoría de estas comarcas viven la expansión vi- 
tivinícola del siglo XIX truncada por la Filoxera, y casi todas ellas reemprenden la actividad vitivinícola durante el primer tercio del siglo Xx y viven el conflicto rabasaire que polarizará las relaciones sociales agrarias de producción en Catalunya ${ }^{52}$.

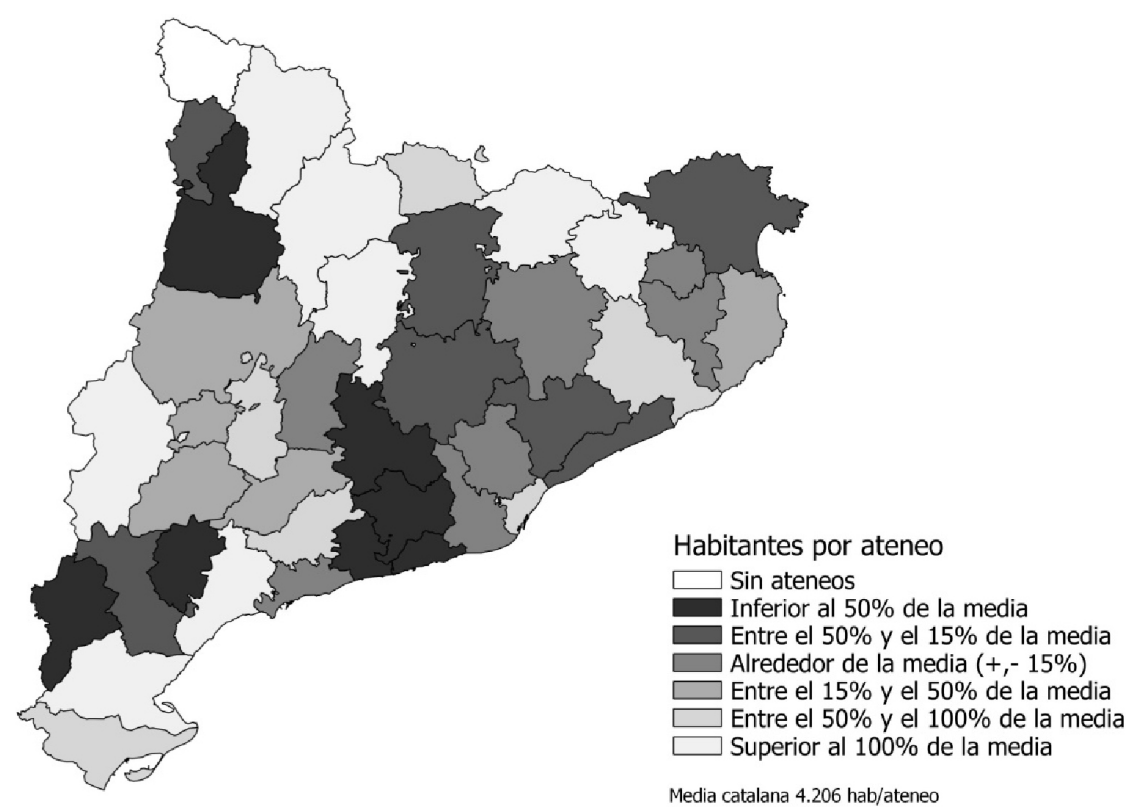

Mapa 8

Densidad asociaciones culturales y recreativas en Catalunya, 1921-1936

Fuente: Elaboración propia a partir de la BDACC del grupo de investigación ISOCAC-URV

Del total de 977 entidades culturales y recreativas creadas entre 1901 y 1936, 198 (un 20\%) se denominan ateneos ${ }^{53}$.

52 Pomés, 2000. Mayayo, 1995. Arnabat y Gavaldà, 2015, p. 169-193.

53 Entre los que hay que destacar: Ateneu Feliuà de Sant Feliu de Codines (1902), Ateneu de Sant Vicenç de Castellet (1903), Ateneu de la Rosa d'Or de Caldes d'Estrac (1904), Ateneu Científic-Social del Berguedà (1907), Ateneu Pradenc de Prades (1914). Ateneos 
El quinquenio central republicano (1931-1936) se caracterizó en el plano cultural por el influjo del movimiento ateneísta. Hecha excepción de la etapa de la Mancomunitat (1914-1923), los intereses de los ateneos coincidían en lo referente a la ciudadanía republicana. La vertiente pedagógica ateneísta - concebida como «universidad popular»- suponía una vía fundamental para incidir en la politización y defensa de luchas sectoriales, como muestra el ejemplo del Ateneu Cultural de Defensa Obrera de les Cases Barates de Can Tunis en Barcelona formado en 1930.

¿Hasta qué punto los ateneos actuaron como «intelectuales colectivos» en un doble sentido: el estrictamente formativo, que suponía la introducción de los trabajadores en las ciencias sociales y físico-naturales, y el de la vinculación implícita de estos centros con unas culturas políticas determinadas? Ejemplos que parecen afirmar esta hipótesis los encontramos en la vinculación entre la organización política Unió Socialista de Catalunya y el Ateneu Polytèchnycum, asociación surgida de profesores expulsados de la Escuela Industrial (1924) ${ }^{54}$; o en la relación implícita entre movimiento anarquista, el partido comunista Bloc Obrer y Camperol y el Ateneu Enciclopèdic Popular.

Este último ejemplo es útil para remarcar su aportación en torno a la vinculación entre conciencia social y política. El Ateneu Enciclopèdic Popular impulsó el congreso dedicado a la Educación Social (1931), con el

que se diversifican temática y políticamente: Ateneu Democràtic Regionalista del Poble Nou de Barcelona (1902), Ateneu Cultural i Esportiu Badaloní (1903), Ateneu Obrer Santboià (1905), Ateneo Obrero Autonomista de San Gervasio de Barcelona (1906), Ateneu Republicà Federal del districte onzè de Barcelona (1906), Ateneo Obrero Tradicionalista de Parma de Barcelona (1907), Ateneu Obrer de Canet de Mar (1907), Ateneu Pi i Margall de la Bisbal d'Empordà (1908), Ateneu Obrer Racionalista del carrer Vallespir de Barcelona (1909), Ateneu Sindicalista de Barcelona (1909), Ateneu La Fraternitat de Sant Sadurní d'Anoia (1910), Ateneu Republicà de Sant Pere de Riudebitlles (1911), Ateneu Pi i Margall de la Barceloneta (1912), Ateneu Instructiu Radical del districte sisè de Barcelona (1913), Ateneu Obrer de Mora la Nova (1915), Ateneu Nacionalista Verdager de Barcelona (1917), Ateneu Agrícola Lavern de Subirats (1918), Ateneu Republicà d'Esterri d'Àneu (1920), Ateneu Socialista de Barcelona (1923), Ateneo Cultural Patriótico Deportivo Maria Cristina de Barcelona (1925), Ateneu Republicà Català de Cornellà (1930), Ateneo Libertario Faros de Barcelona (1930), Ateneu Democràtic Republicà de Begues (1931), Ateneu Llibertari de Balsereny (1932), Ateneu d'Esquerra Republicana de Gironella (1932), Ateneu Sindicalista de Vilanova (1934). Fuente: BDACC [ISOCAC-URV].

${ }_{54}$ Ateneu Polytechnicum. Estatuts, (1936), p. 3. Sirva como muestra que en el curso 1935-1936 impartieron asignaturas el Dr. Josep Trueta: «La medicina en la casa», Gonçal de Reparaz: «Geografía» o Andreu Nin: «Literatura rusa». 
objetivo de tratar aspectos del medio ambiente y biomédicos que incidían en la práctica educativa formal e informal. La entidad también se hizo eco de nuevas culturas políticas como la marxista y difundió el influjo de la literatura soviética, e impulsó la campaña contra el paro obrero forzoso y el curso 1931-1932 organizó un ciclo sobre Economía Política. Este tipo de iniciativas llevó al AEP - a través de la Universidad de Barcelona, el CADCI y el Ateneu Polytèchnycum - a formalizar los estudios universitarios para obreros. Este objetivo fue alcanzado mediante las actividades de la Sección de Estudios Políticos y Sociales, el portavoz de la cual fue la Revista Ateneu (diciembre 1931-marzo-1932).

Durante el período republicano, el Enciclopèdic alcanzó alrededor de 20.000 asociados, emprendió iniciativas de recuperación del patrimonio, participó en la constitución de la Aliança Obrera Antifeixista (1933) y dio apoyo a la organización de la Olimpiada Popular (1935-1936). A principios de 1936 el Ateneu se adhirió - con cinco asociaciones mása la campaña pro-catalanització de todas las entidades culturales y asociativas. El 26 de noviembre de 1936 hizo un homenaje - junto a otras entidades como el Ateneu Polytechnycum - a uno de sus fundadores, el abogado Francesc Layret. En síntesis, la sucinta trayectoria de esta entidad denota el decidido compromiso pedagógico en torno a unos referentes culturales e ideológicos alternativos al industrialismo y a la cultura política tardorestauracionista hegemónica en el marco de los efectos de la crisis de acumulación capitalista de 1929.

Como proyección, debemos plantear que la guerra civil (1936-1939) incidió en la vida ateneísta - adecuando su función a las nuevas necesidades revolucionarias - , pues muchos de sus asociados tuvieron que ir al frente de combate. Con todo, el Enciclopèdic acogió la fundación del Sindicato de Dibujantes Profesionales de Cataluña (1936). La última Junta del Ateneu fue en agosto de 1937, aunque la programación de actividades se mantuvo el curso 1937-38. En este periodo, el Ateneu se adhirió a campañas de apoyo en el frente de guerra y se solidarizó con la Alianza de Intelectuales para la Defensa de la Cultura.

\section{A modo de conclusión: ¿Qué aporta culturalmente la estructura ateneísta catalana contemporánea?}

Del cruce de las estadísticas utilizadas en el estudio con la historicidad ateneísta en Catalunya podemos colegir diversos aspectos. Primero, en el 
movimiento ateneísta en Catalunya nos encontramos con una relación entre identidad territorial-comarcal, lógicas de agrarización/desagrarización $\mathrm{y}$, en consecuencia, la generación de espacios de sociabilidad ${ }^{55}$.

Segundo, como podemos ver en los mapas aportados durante el período 1836-1936, el ateneísmo se va expandiendo desde las comarcas litorales y prelitoriales hacia el interior del país, de forma continua e ininterrumpida, creándose una media de un ateneo nuevo por cada 4.000/6.000 habitantes. La dinámica del ateneísmo catalán se localiza en las comarcas de la Región Metropolitana de Barcelona y en comarcas litorales, prelitorales y de interior: Penedès, Priorat, Ribera d'Ebre y Terra Alta, Noguera, Pallars Jussà, Pla de l'Estany, Baix Camp, L'Anoia, Alt i Baix Empordà, Gironès y Pla de l'Estany.

Tercero, debe destacarse el papel de los ateneos en el proceso de alfabetización de las clases subalternas. Mientras que en 1860 tan sólo el $25 \%$ de la población catalana sabía leer y escribir, setenta años más tarde (1930) ya sabía leer y escribir el 75\%. La trayectoria que hemos descrito es ejemplo de articulación de espacio de socialización cultural. Como señala Pere Solà, parecen muy claras «las conexiones entre el desarrollo asociativo comunitario (densidad y variedad de la oferta de sociedades voluntarias) y el desarrollo cultural y la alfabetización de la población» ${ }^{56}$.

Cuarto, los ateneos adscritos a las clases populares - como espacios de sociabilidad fundamentados en la solidaridad horizontal - favorecieron el desarrollo de una ciudadanía política y de una sociedad civil autónoma respecto del estado, del poder económico y de la Iglesia; y actuaron como resortes modernizadores culturales y de transformación social ${ }^{57}$. Aunque dichos resortes fueron materializándose de forma mediata. Así, los ateneos del siglo XIX y primer tercio del XX tenían un sesgo de género muy claro - sólo podían ser socios los hombres - , acorde con una sociedad que reservaba para el género masculino la esfera pública, y para el femenino la privada. A partir de los años ochenta del siglo XIX, algunos ateneos permitieron la entrada de las mujeres, eso sí, siempre acompañadas de un hombre (el hermano, el marido o el padre) y para determinadas actividades, como el baile o el teatro, pero nunca como socias de pleno dere-

55 Agulhon, 1981 y 1986; Canal, 1992 y 2002; Guereña, 1999 y 2003; Solà, 1983(a), 1994, 1998; y Arnabat y Ferré, 2015.

56 Solà, 1998, p. 15. Solà, 1983 (b), p. 393-402.

57 Solà, 1997, p. 169-193. Arnabat, 2015, p. 383-445. 
cho. No será hasta bien entrado el siglo Xx que las mujeres podrán hacerse socias de algunas entidades culturales, más bien pocas: el Ateneu Igualadí de la Clase Obrera en 1912; el Ateneu Català de Sallent en 1916 o el Ateneu Sindicalista de Badalona en $1917^{58}$. A partir de inicios del siglo XX se inicia un proceso que llevará a la creación de secciones y/o asociaciones femeninas: Sociedad instructiva La Progresiva Femenina de Sabadell (1900), Institut de Cultura i Biblioteca Popular de la Dona (1909), Club Femení i d'Esports de Barcelona (1928), Unió Catòlica Femenina de Falset (1923) o Ateneu Republicà Femení de Barcelona (1928). Aunque, no será hasta la Segunda República que las mujeres se integrarán de forma importante en las asociaciones culturales catalanas y organizarán sus propias entidades: Lyceum Club de Barcelona (1931), Unió Femenina Camp de l'Arpa de Barcelona (1931), Associació Femenina d'Arenys de Munt (1932) o Lliga Laica Femenina (Sabadell, 1932) ${ }^{59}$.

Quinto, la red ateneísta fue un «movimiento» de construcción cultural que permitió dotar a las clases populares y medias de referentes intelectuales y de conocimientos teórico-prácticos a fin de articular una ciudadanía cívico-política. Los ateneos incidieron en el comportamiento democrático deliberativo, el cual conllevaba comprender los debates como elementos enriquecedores, asumir las decisiones colegiadas y defenderlas como propias.

Sexto, en cuanto a la tarea desarrollada por el ateneísmo en el ámbito pedagógico debemos destacar que fue el canal de introducción de innovaciones educativas europeas: desde la Escuela Moderna o racionalista a las teorías freinetistas cooperativistas ${ }^{60}$. De hecho, los primeros centros donde se aplicaron estas innovaciones educativas fueron las escuelas de los ateneos y en los centros instructivos, es decir, en los espacios de la sociabilidad popular. Nos puede servir de ejemplo la Escuela Universal relacionada con la cooperativa Model del segle XX y dependiente del Ateneo Obrero Racionalista del barrio de Sants (Barcelona). Esta escuela aplicaba los métodos racionalistas, tal y como relata el alumno y posterior maestro, el anarcosindicalista Josep Peirats: «Los maestros no pegaban a los niños y se aprendía mucho y bien. Era una escuela patrocinada por el Ateneo

\footnotetext{
58 Bosch, 1991(b), pp. 53-60. Arnabat y Ferré, 2015, pp. 41-207.

59 Nash y Borderías, 1995. Luna y Macià, 1998. Duch y Palau, 2015. Duch, 2015. Bussy-Genevois (ed.), 2002. Moreno, 2006.

${ }_{60}$ Núñez, 1992. Solà (Coord.), 1994 (b), 2010. Motilla, 2012, págs, 339-358. Bosch, 1991 (b), p. 103-113.
} 
Obrero de la calle Vallespir, un local bastante grande, con un escenario al fondo, que bien conocíamos.» ${ }^{61}$

Séptimo, el ateneísmo tuvo un papel destacado en la difusión local y comarcal de diversas formas de catalanización político-cultural. Según Josep Fontana y Pere Anguera, ${ }^{62}$ fueron las capas populares las que mostraron mayor consciencia sociolingüística. De hecho, la socialización del catalanismo político, del republicanismo, del socialismo y del anarquismo, serían impensables sin esta red de asociaciones territoriales ateneístas. Y, octavo, por todo ello, el asociacionismo será clave en la socialización política catalana de la segunda mitad del siglo XIX y del primer tercio del siglo $\mathrm{XX}^{63}$.

\section{Fuentes}

BASE DE DADEs DE L'ASSOCIACIONISME CATALÀ Contemporani, 1870-1980 (BDACC) [ISOCAC-URV].

Archivo Histórico Nacional (AHN). Ministerio de Gobernación. Dirección General DE SEgurIDAD, «Resumen de las Sociedades de todas clases existentes en España en el día 1. ${ }^{\circ}$ de enero de 1887, con expresión de su objeto según los datos facilitados a esta Dirección General. Clasificación y objeto». FC_M. ${ }^{\circ}$ _Interior. Legajo 575, expediente 1 .

Archivo General del Gobierno Civil de Barcelona, Fondo de Asociaciones.

Arxiu Històric de Girona. Fondos del Gobierno Civil, Asociaciones.

ArXiu Històric de Lleida. Fondos del Gobierno Civil, Asociaciones.

ArXiu Històric de TARragona. Fondos del Gobierno Civil, Asociaciones.

InSTITUTO DE REFORMAS SociALES, Estadística de la Asociación obrera en $1 .^{\circ}$ de noviembre de 1904, formada por la sección tercera Técnico-Administrativa, Madrid, Imprenta de la Sucesora de M. Minuesa de los Ríos, 1907.

InSTITUTO DE REFORMAS Sociales, Estadística de asociaciones. Censo electoral de asociaciones para la renovación de la parte electiva del Instituto y de las Juntas Sociales y relación de las Instituciones no profesionales de ahorro, cooperación y previsión. En 30 de junio de 1916, Madrid, M. Minuesa de los Ríos, 1917.

\footnotetext{
61 Peirats, 2009.

62 Fontana, 2016. Anguera, 1997. Una visión diferente en Marfany, 2001.

63 Ya establecido en la obra enciclopédica de Galí,1980-1986.
} 


\section{Bibliografía}

Agulhon, Maurice, «Les associations depuis le début du XIX siècle», AgUlHON, Maurice y Bodiguel, Maryvonné, Les associations au village, Le Paradou, Actes Sud, 1981, pp. 9-37.

AgulHON, Maurice, «La sociabilité est-elle objet d'histoire?», FRANÇOIS, Etienne (ed.), Sociabilité et société bourgeoise en France, en Allemagne et en Suisse (1750-1850), Paris, Recherche sur les Civilisations, 1986, pp. 13-22.

AISA, Ferran, Una història de Barcelona. Ateneu Enciclopèdic Popular, Barcelona, Virus, 2000.

Alarcón, Manuel R, El derecho de asociación obrera en España (1839-1900), Madrid, Revista del Trabajo, 1975.

Anguera Nolla, Pere, El Centre de Lectura de Reus. Una institució ciutadana, Barcelona, Edicions 62, 1977.

Anguera, Pere, El català al segle XIX, De llengua del poble a llengua nacional, Barcelona, Empúries, 1997

Anguera, Pere, Societat, sociabilitat i ideologia a l'àrea reusenca, Reus, Asociació d'Estudis Reusencs, 1999.

Arnabat, Ramon y Ferré, Xavier, Ateneus. Cultura i Llibertat, Barcelona, Federació d'Ateneus de Catalunya, 2015.

ARnABAT, Ramon y FERRÉ, Xavier, «Sociabilitat: entre la teoría i la historiografia», Duch, Montserrat. Arnabat, Ramon, FERrÉ, Xavier (eds.), 2015, p. 19-62.

Arnabat, Ramon y Gavaldè, Antoni, «Sociabilidad y asociacionismo como factores de movilización social: el mundo rural catalán entre 1870 y 1980», en CAstillo, Santiago y Duch, Montserrat (Coords.): Sociabilidades en la historia, Madrid, Catarata, 2015, p. 169-193.

ARnABAT, Ramon, «Associacionisme i sociabilitat al Penedès (1868-1970)», DuCH, Montserrat. ArnABAT, Ramon, FerRé, Xavier (eds.), 2015, p. 383-445.

ARNABAT, Ramon, «Sociabilidad, modernización y ciudadanía en la España del siglo XIX», texto inédito presentado al Simposio de la red de hispanistas decimonónicos celebrado en Londres los días 8 y 9 de abril de 2016.

Artís, Pere, El cant coral a Catalunya, 1891-1979, Barcelona, Barcino, 1980.

Ateneu PolyteChNiCUM. BARCELONA, Estatuts (1-II-1936).

Bernal, Antonio y LACroIX, Jacques, «Aspects de la sociabilité andalouse. Les associations sévillanes (XIX-XX s.)», Melanges de la Casa Velázquez, XI, 1975, pp. 435-507.

Bosch, Amàlia, «El paper de les associacions en l'ensenyament i la formació cultural», Armengol, Gemma (Ed.), Associacions. Cultura i societat civil a Catalunya., Tarragona. El Mèdol, 1991 (a), p. 103-113.

Bosch, Amàlia, Els ateneus de Catalunya, Barcelona, Federació d'Ateneus de Catalunya, 1991(b). 
Bussy-Genevois, Danièle (Ed.), Les Espagnoles dans l'histoire. Une sociabilité démocratique (XIX-XXe siècles), Saint-Denis, Presses Universitaires de Vincennes, 2002.

Callahan, William, La Iglesia catòlica en España (1875-2002), Barcelona, Crítica, 2002.

CANAL, Jordi «La sociabilidad en los estudios sobre la España contemporánea», Historia contemporánea, 7, 1992, pp. 183-205.

CANAL, Jordi, «La sociabilidad en los estudios sobre la España contemporánea: una revisión», MAZA, Elena [coord.], 2002, pp. 35-57.

CANAL, Jordi et al., «VII Jornadas de historia local: espacios de sociabilidad en Euskal Herria», Vasconia. Cuadernos de historia - Geografía, 2003, pp. 11523.

Cao Costoya, David, Societat $i$ sociabilitat. El Cercle Literari i els inicis de l'associacionisme recreatiu cultural i polític a Vic (1848-1902), CatarrojaBarcelona, Editorial Afers, 2015.

CArbonell, Jaume, Josep Anselm Clavé i el naixement del Cant coral a Catalunya: 1850-1874, Cabrera de Mar, Galerada, 2000.

CArbonell, Jaume, La Societat Cultural Euterpe fundada per Clavé. El Prat de Llobregat, Rúbrica Editorial, 2007.

CARrasco, Raphaël (Ed.), Solidarités et sociabilités en Espagne (XVI-XX siècles), Paris, Les Belles Lettres, 1991.

Casassas, Jordi, L'Ateneu Barcelonès, dels seus orígens als nostres dies, Barcelona, IMHB, 1986.

Comas, Montserrat, Lectura i biblioteques populars a Catalunya:1793-1914, Barcelona, Curial-Publicacions de 1'Abadia de Montserrat, 2001.

Comas, Montserrat, Verticals parterres. La planificació bibliotecària a Catalunya. L'exemple del Penedès, Vilafranca del Penedès, Institut d'Estudis Penedesencs, 2017.

Comas, Montserat, Oliva Pascuet, Víctor: Llums entre ombres. 6 biblioteques singulars a la Catalunya contemporània, Organisme Autònim del Patrimoni, Vilanova i La Geltrú, 2011.

Cucó, Josepa, El quotidià ignorat. La trama associativa valenciana, Valencia, Ediciones Alfons el Magnànim, 1991.

DuCH, Montserrat, «El genero de la sociabilidad europea contemporània: noas para su estudio», CAstillo, Santiago y Duch, Montserrat (Coords.), Sociabilidades en la Historia, Madrid, Catarata, 2015 (a), p. 115-132.

Duch, Montserrat y PALAU, Montserrat, «La socialización de los saberes femeninos: el Instituto de Cultura y Biblioteca Popular para la Mujer, Barcelona (1900-1936)», Historia Social, núm. 82, 2015, pp. 133-147.

Duch, Montserrat, ARnABAT, Ramon y Ferré, Xavier (Eds.), Sociabilitats a la Catalunya contemporània. Temps i espais en conflicte, Barcelona, Publicacions de l'Abadia de Montserrat, 2015. 
ESCALERA, Reyes, «Sociabilidad, relaciones de poder y cultura política en Andalucía», MORENO, Isidoro y AGUAdO, Juan (Coords.), Expresiones culturales andaluzas, Sevilla, Aconcagua Libros, 2012, pp. 127-163.

EsteVe, Oriol, «Les bandes de música de la comarca del Montsià: de cultura popular a eina de cultura contemporània», Raïls, núm. 27, 2011, pp. 80-165.

Estudios DE Asociacionismo y SociABILIDAD, Grupo, España en sociedad. Las asociaciones a fínales del siglo XIX, Cuenca, Ediciones de la Universidad de Castilla-La Mancha, 1998.

Ferraté GILI, Joan, «Congressisme», Foment, 91, 16-IV-1911.

Ferré TrILl, Xavier: «La Biblioteca del Centre de Lectura de Reus», COMAS/ OLIVA, 2011, pp. 18-41.

Fontana, Josep, La fi de l'Antic Règim i la industrializació, 1787-1868, Barcelona, Edicions 62, Barcelona, 1987.

Fontana, Josep, La revolució liberal a Catalunya, Vic-Lleida, Eumo-Pagès, 2003.

Fontana, Josep, La época del liberalismo. Vol. 6 Historia de España, MadridBarcelona, Marcial Pons-Crítica, 2007.

FontanA, Josep, La formació d'una identitat. Una història de Catalunya, Vic, Eumo editorial, 2016.

Fornós, Alex y Queralt, M. Carme Les bandes de música a les comarques de Tarragona, Tarragona, Diputació de Tarragona, 2003.

GALÍ, Alexandre Història de les institucions i del moviment cultural de Catalunya (1900-1936), Barcelona, Fundació Alexandre Galí, 1980-1986.

GARRIDO, Samuel, Los trabajadores de las derechas, Castelló, Diputació de Castelló, 1986.

Gort JuAnPere, Ezequiel y Gomis EsPada, Josep, Annals de l'Orfeó Reusenc (1918-1993), Reus, Orfeó Reusenc, 1994.

GüEll y MERCADER, Josep, Coses de Reus (Recorts d'un jove que ja no ho es), Reus, Establiment Tipografich de Eduart Navás, 1900.

GuEREÑA, Jean-Louis, «La sociabilidad en la España contemporánea», SÁNCHEZ, Isidoro y VilLENA, Rafael (eds.), 1999, pp. 11-43.

GuEREÑA, Jean-Louis, «Espacios y formas de la sociabilidad en la España contemporánea», Hispania, vol. LXIII, núm.214 (2003), pp. 409-413.

GuEREÑA, Jean-Louis et al., «Dossier: Espacios y formas de la sociabilidad en la España contemporánea», Hispania, vol. LXIII, núm. 214, 2003, pàgs. 407774.

GuEREÑA, Jean-Louis, Sociabilidad, cultura y educación en Asturias bajo la Restauración (1875-1900), Oviedo, Real Instituto de Estudios Asturianos, 2005. LEDUC, Édouard, Anatole France avant l'oubli, París, Éditions Publibook, 2004.

Luis Martín, Francisco de y ARIAs, Luís, Las Casas del Pueblo socialistas en España, 1900-1936, Barcelona, Ariel, 1979. 
LUNA, Joana y MACIÀ, Elisenda, «L'associacionisme femení: catolicisme social, catalanisme i lleure», NASH, Mary (Ed.), Més enllà del silenci: les dones a la historia de Catalunya, Barcelona, Generalitat de Catalunya, 1998, pp. 227-242.

«Manifest de L'Ateneu EnciClopèdic» [OCTUbre, 2006], Enciclopèdic Noticiari, 32, III Època, gener de 2007, p. 5-6.

MARFANY, Joan Lluís, La llengua maltractada: el català i el castellà a Catalunyadel segle XVI al segle XIX, Barcelona, Empúries, 2001.

Martin, Luis P. y Brenot, Anne M. (Eds.), Les sociabilités dans le monde hispanique (XVIIIè-XXè siècles). Formes, lieux et représentations, Valenciennes, Presses Universitaires de Valenciennes, 2000.

Mata [Miarons], E[ugeni], «Centro de Lectura. Su Biblioteca», El Eco del Centro de Lectura, 31, 31-X-1897.

Mato, Ángel, La Atenas del Norte. Ateneos, sociedades culturales y bibliotecas populares en Asturias (1876-1937), Oviedo, KRK Ediciones, 2008.

MAURICE, Jacques et. al, «Dossier» en Estudios de Historia Social, núm. 50-51, 1989, p. 133-471.

Mayayo, Andreu, De pagesos a ciutadans. Cent anys de sindicalisme i cooperativisme agrari a Catalunya, 1893-1994, Catarroja-Barcelona, Editorial Afers, 1995.

MAZA, Elena, «Las clases Populares en España: continuidad y transformaciones en su perfil asociativo (1887-1930)», Investigaciones históricas. Época Moderna y Contemporánea, núm.15,1995, p. 297-314.

MAZA, Elena, «La horizontalidad de las solidaridades. El mutualismo en la España contemporánea», Ayer, núm.25, 1997, p. 73-102.

MAZA, Elena (Coord.), Sociabilidad en la España contemporánea: historiografía y problemas metodológicos, Valladolid, Universidad de Valladolid, 2002.

MAZA, Elena (Coord.), Asociacionismo en la España contemporánea: vertientes y análisis interdisciplinar, Valladolid, Universidad de Valladolid, 2003.

Moral SANDOVAL, Enrique, «Las casas del pueblo en el socialismo español», en ARnABAT, Ramon y Duch, Montserrat (eds.), Historia de la sociabilidad contemporánea. Del asociacionismo a las redes sociales, València, PUV, 2014, p. 123-144.

Morales, Manuel, «La sociabilidad popular en Málaga, 1840-1874: de la tutela burguesa a la afirmación de una identidad diferenciada», Estudios de Historia Social, núms. 50-51, 1989, pp. 243-271.

MorALES, Manuel, «La sociabilidad popular en la Andalucía del siglo XIX: elementos de permanencia y tradición», Baetica, núm.15, 1993, pp. 383-395.

Morales, Manuel, «Un espacio propio. Sociabilidad e identidad obrera en Andalucía», Historia Social, núm.56, 2006, pp. 53-69.

Moreno, Mónica, «Mujeres y sociabilidad laica (1875-1931)», Asparkia, núm.17, 2006, p. 61-80. 
Motilla, Xavier, «Bases bibliográficas para una historia de la sociabilidad, el asociacionismo y la Educación en la España Contemporánea», Historia de la Educación. Revista Interuniversitaria, núm. 31 2012, p. 339-358.

NASH, Mary y BorderíAs, Cristina, «La presència de la dona», CASASSAS, Jordi (dir.), L'època dels nous moviments socials, 1900-1930, Barcelona. Enciclopèdia Catalana, 1995, pp. 162-178.

NúÑEZ, Clara E., La fuente de la riqueza. Educación y desarrollo económico en la España contemporánea, Madrid, Alianza, 1992.

PeIRAts, Josep, De mi paso por la vida. Memorias, Barcelona, Flor de Viento, 2009.

Poblet, Josep M, Josep Anselm Clavé i la seva època, Barcelona, Edicions 62, 1973.

Pomés, Jordi, La Unió de Rabassaires. Barcelona, Publicacions de l'Abadia de Montserrat, 2000.

Ponce, Santi, El Casino de Vic, 1848-2008, Vic, Eumo, 2008.

QuesadA, Santiago, La historia del Casino de Cadaqués (180-1938), Cadaqués, Societat L'Amistat, 2014.

RAmón, Antoni y AlCÁZAR, Iván, «L’arquitectura dels Ateneus», Arnabat y FERRÉ, 2015, p. 391-404.

RECASENS I MERCADÉ, Josep, «Associacionisme i colectivisme», Athenaeum, 109, juliol 1911, p. 154-155.

RiBA I GuMÀ, Salvador, L’Ateneu igualadí de la classe obrera (1863-1939), Igualada, Ateneu Igualadí, 1988.

Rodón, Maria A., Inventari de les associacions polítiques i obreres inscrites en el Govern Civil de Barcelona des de l'any 1877 fins 1936, Barcelona, ANABAD, 1982.

Roig Rosich, Josep M., La Dictadura de Primo de Rivera a Catalunya. Un assaig de repressió cultural, Barcelona, Publicacions de l'Abadia de Montserrat, 1992.

SÁncheZ, Isidoro y Villena, Rafael (eds.), Sociabilidad fin de siglo, Cuenca, Universidad de Castilla-La Mancha, 1999.

Sans Orenga, Manuel, Breu historia de l'Ateneu Barcelonès, Barcelona, Ateneu Barcelonès, 1983.

SAntAnA, Manuel «Els casinos i ateneus: esbarjo, educació, política i cultura a Mallorca a finals del segle XIX», Bolletí de la Societat Arqueològica Lul.liana, núm. 57, 2001, p. 221-236.

SEGON CONGRÉS REGIONAL D'ATENEUS I SoCIETATS DE CULTURA - SEGUNDO CONGRESO REGIONAL DE ATENEOS Y SOCIEDADES DE CULTURA, Ateneu de Vilanova i la Geltrú, Imprenta Diario de Villanueva y Geltrú, 1912, p. 8-10.

SERrA, Sebastià y COMPANY, Arnau (Coords.), El moviment associatiu a les Illes Balears, Des de finals del segle XIX fins l'actualitat, Palma de Mallorca, IEB, 2001. 
SolÀ, Pere, Els ateneus obrers i la cultura popular a Catalunya (1900-1939), Barcelona, La Magrana, 1978.

SolÀ, Pere, Cultura popular, educació i societat al Nord-Est català (1887-1959): assaig sobre les bases culturals i educatives de la Catalunya rural contemporània, Girona, Col·legi Universitari, 1983 (a).

SolÀ, Pere, «Acerca del modelo asociativo de culturalización popular de la Restauración», GuEREÑA, Jean-Lous y TiAnA, Alejandro (Eds.), Clases populares, cultura, educación. Siglos XIX-XX, Madrid, UNED-Casa de Velázquez, 1983 (b), p. 393-402.

SolÀ, Pere, «Esbarjo i educació en l'espai i el temps (segles XIX i XX): Anàlisi del model Casino», Espai i temps d'oci en la història. XI Jornades d'Estudis d'Història Local, Palma de Mallorca, Institut d'Estudis Baleàrics, 1993, p. 223-235.

Sola, Pere, Història de l'associacionisme català contemporani. Barcelona i comarques de la seva demarcació, Barcelona, Generalitat de Catalunya, Barcelona, 1994.

Sola, Pere, (Coord.), Educació i Història. Revista d'Història de l'Educació, núm. 1, 1994.

SolÀ, Pere, «El paper de l'associacionisme d'esbarjo a Catalunya a les primeres dècades de l'Estat liberal (1833-1874) pel que fa a la "producció" de la festa moderna», CAPDEVILA, Joaquim y GARCÍA, Agustí (Ed.), La festa a Catalunya. La festa com a vehicle de sociabilitat i d'expressió política, Barcelona, Publicacions de l'Abadia de Montserrat, 1997, p. 169-193.

SolA, Pere, Itineraris per la sociabilitat meridional catalana. L'associacionisme i la cultura popular a la demarcació de Tarragona (1868-1964), Tarragona, Diputació de Tarragona, Tarragona, 1998.

SolÀ, Pere (Coord.), Educació i Història. Revista d'Història de l'Educació, núm. $16,2010$.

ZozayA, María, Del Ocio al negocio: redes y capital social ene le casino de Madrid: 1836-1901, Madrid, La Catarata, 2007.

ZoZAYA, María, Identidades en juego: formas de representación social del poder de la élite en un espacio de sociabilidad masculino, 1836-1936, Madrid, Siglo XXI, 2015.

VALín, Alberto (Dir), La Sociabilidad en la historia contemporánea: reflexiones teóricas y ejercicios de anàlisis, Ourense, Duen de Bux, 2001.

VIRELlA, Albert, «L'Ateneu de Vilanova», Diari de Vilanova, 16-IV-1977.

Winston, Colin M., La clase trabajadora y la derecha española. 1900-1936, Madrid, Cátedra, 1989. 


\section{Financiación}

Este texto se enmarca en el programa de investigación del proyecto Sociabilidades. Espacios de constitución de la ciudadanía en Cataluña (1868-1939) [HAR 2014-54230] del Ministerio de Economía y Competitividad.

\section{Datos de los autores}

Ramon Arnabat Mata (ramon.arnabat@urv.cat), historiador y profesor de Historia contemporánea en la Universitat Rovira i Virgili. Ha centrado sus investigaciones en la revolución y la contrarrevolución durante la primera mitad del siglo XIX, la historia de la sociabilidad y los movimientos sociales en los siglos XIX y XX y la Guerra Civil española y el primer Franquismo. Recientemente ha publicado: Atac i defensa de la rereguarda. Els bombardeigs franquistes sobre les comarques de Tarragona i les Terres de l'Ebre, 1936-1939 (2013), (con M. Duch) Historia de la sociabilidad contemporánea (2014), (con M. Duch y X. Ferré), Sociabilitats a la Catalunya contemporània (2015) y (con X. Ferré), Ateneus. Cultura i llibertat. Associacionisme a la Catalunya contemporània (2015).

Xavier Ferré Trill (xavier.ferre@urv.cat), historiador del pensamiento político contemporáneo, es profesor del Departamento de Pedagogia (URV). Recientemente ha publicado: (con Ramon Arnabat): Ateneus. Cultura i llibertat. Associacionisme a la Catalunya contemporània (2015), Manuel de Pedrolo i la nació (19571982), Joan Poblet i Teixidó: la qüestió agrària com a qüestió nacional (2017). 